\title{
Efficacy of melatonin, IL-25 and silL-17B in tumorigenesis-associated properties of breast cancer cell lines
}

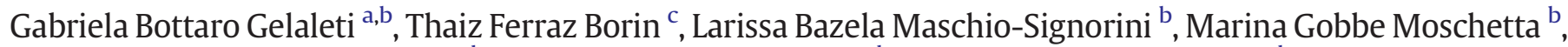 \\ Bruna Victorasso Jardim-Perassi ${ }^{\mathrm{b}}$, Guilherme Berto Calvinho ${ }^{\mathrm{b}}$, Mariana Castilho Facchini ${ }^{\mathrm{b}}$, \\ Alicia M. Viloria-Petit ${ }^{\mathrm{d}}$, Debora Aparecida Pires de Campos Zuccari ${ }^{\mathrm{a}, \mathrm{b}, *}$
}

\footnotetext{
a Universidade Estadual Paulista "Júlio de Mesquita Filho" (UNESP/IBILCE), Programa de Pós-Graduação em Genética, São José do Rio Preto, SP, Brazil

${ }^{\mathrm{b}}$ Faculdade de Medicina de São José do Rio Preto (FAMERP). Laboratório de Investigação Molecular do Câncer (LIMC), São José do Rio Preto, SP, Brazil

c Tumor Imaging Angiogenesis Laboratory, Georgia Cancer Center, Augusta University, Augusta, GA, United States
}

d Department of Biomedical Sciences, Ontario Veterinary College, University of Guelph, Guelph, Ontario, Canada

\section{A R T I C L E I N F O}

\section{Article history:}

Received 20 March 2017

Received in revised form 7 June 2017

Accepted 13 June 2017

Available online 15 June 2017

\section{Keywords:}

Breast cancer

Melatonin

Interleukin-25

Interleukin-17E

Interleukin-17B

Apoptosis

VEGF

\begin{abstract}
A B S T R A C T
Mammary tumorigenesis can be modulated by melatonin, which has oncostatic action mediated by multiple mechanisms, including the inhibition of the activity of transcription factors such as NF- $k$ B and modulation of interleukins (ILs) expression. IL-25 is an active cytokine that induces apoptosis in tumor cells due to differential expression of its receptor (IL-17RB). IL-17B competes with IL-25 for binding to IL-17RB in tumor cells, promoting tumorigenesis. This study purpose is to address the possibility of engaging IL-25/IL-17RB signaling to enhance the effect of melatonin on breast cancer cells. Breast cancer cell lines were cultured monolayers and 3D structures and treated with melatonin, IL-25, silL-17B, each alone or in combination. Cell viability, gene and protein expression of caspase-3, cleaved caspase-3 and VEGF-A were performed by qPCR and immunofluorescence. In addition, an apoptosis membrane array was performed in metastatic cells. Treatments with melatonin and IL-25 significantly reduced tumor cells viability at $1 \mathrm{mM}$ and $1 \mathrm{ng} / \mathrm{mL}$, respectively, but did not alter cell viability of a non-tumorigenic epithelial cell line (MCF-10A). All treatments, alone and combined, significantly increased cleaved caspase-3 in tumor cells grown as monolayers and 3D structures $(\mathrm{p}<0.05)$. Semi-quantitative analysis of apoptosis pathway proteins showed an increase of CYTO-C, DR6, IGFBP-3, IGFBP-5, IGFPB-6, IGF-1, IGF-1R, Livin, P21, P53, TNFRII, XIAP and hTRA proteins and reduction of caspase-3 $(\mathrm{p}<0.05)$ after melatonin treatment. All treatments reduced VEGFA protein expression in tumor cells $(\mathrm{p}<0.05)$. Our results suggest therapeutic potential, with oncostatic effectiveness, pro-apoptotic and anti-angiogenic properties for melatonin and IL-25-driven signaling in breast cancer cells.
\end{abstract}

(C) 2017 Elsevier Inc. All rights reserved.

\section{Introduction}

The breast tumor microenvironment is composed of several cell types, including inflammatory and endothelial cells, fibroblasts and adipocytes, among others [1-3]. Mutual interactions between malignant epithelial cells and the surrounding microenvironment, in part mediated by cytokines and their receptors, modulate the behavior of malignant cells and drive tumor progression [3-6]. Thus, it is important to identify these microenvironmental mediators of tumor progression as well as the strategies to successfully target them [7].

\footnotetext{
* Corresponding author at: Laboratório de Investigação Molecular do Câncer (LIMC) Faculdade de Medicina de São José do Rio Preto (FAMERP), Avenida Brigadeiro Faria Lima, 5416, Vila São Pedro, São José do Rio Preto, (SP) 15090-000, Brazil.

E-mail addresses: gabi_b_g@yahoo.com.br (G.B. Gelaleti), thaiz80@yahoo.com.br (T.F. Borin), larissa_maschio@hotmail.com (L.B. Maschio-Signorini), marinagobbe@hotmail.com (M.G. Moschetta), gbc1991@gmail.com (G.B. Calvinho), vinagretefamerp@yahoo.com.br (M.C. Facchini), aviloria@uoguelph.ca (A.M. Viloria-Petit), debora.zuccari@famerp.br (D.A.P. de Campos Zuccari).
}

Melatonin ( $\mathrm{N}$-acetyl-5-methoxytryptamine), an endogenous molecule, is a conserved indolamine synthesized from tryptophan which is mainly produced by the pineal gland and other nonendocrine organs [8]. Different mechanisms of melatonin anti-tumor action have been proposed, regulating a variety of cellular pathways. These include oncostatic and anti-inflammatory effects, increased local immunity [8-11], cellular antioxidant capacity $[12,13]$, upregulation of tumor suppressor gene expression [14], control of cell differentiation and proliferation [15,16], and induction of apoptosis [17]. Melatonin also blocks the activity of transcription factors such as nuclear factor- $\kappa \mathrm{B}(\mathrm{NF}-\kappa \mathrm{B})$, inhibiting the expression of cytokines, metalloproteinases and the vascular endothelial growth factor (VEGF) [18-20]. Furthermore, Alvarez-García et al. [10] and Ordoñez et al. [8] have shown that melatonin also modulates pro-inflammatory cytokines, and this might impact the tumor microenvironment.

A family of six pro-inflammatory cytokines comprised of interleukin (IL) 17A-F [21-24], have been considered potent activators of innate immunity, promoting a protective tumor immunity [25]. Unlike the pro- 


\section{Abbreviations}

ACTB beta-actin

ANOVA analysis of variance

au arbitrary unit

APAF1 apoptotic protease activating factor 1

Bax Bcl-2-like protein 4

BCA bicinchoninic acid

Bcl-2 B-cell lymphoma 2

cAMP receptor protein

cDNA complementary DNA

CYTO-C cytochrome C

DAPI 4',6-diamidino-2-phenylindole

DMEM Dulbecco's modified Eagles' medium

DMSO dimethylsulfoxide

DR6 death receptor

3D tridimensional

ELISA enzyme-linked immunosorbent assay

ER estrogen receptor

GAPDH glyceraldehyde-3-phosphate dehydrogenase

GPCR G protein-coupled receptors

G13D mutation in an amino acid substitution at position 13

HIF-1 $\alpha$ hypoxia-inducible factor 1-alpha

HRP horseradish peroxidase

hTRA family of serine proteases

HUMEC basal serum-free medium

IF immunofluorescence

IGF-1 insulin-like growth factor 1

IGFBPs insulin-like growth factor-binding protein

IGFR-1 insulin-like growth factor 1 receptor

ILs interleukins

ILR interleukin receptor

K-ras kirsten rat sarcoma viral oncogene homolog

MCF-7 human breast adenocarcinoma cell line estrogen positive

MDA-MB-231 human breast adenocarcinoma cell line

triple negative

MAPK mitogen-activated protein kinases

MCF-10A human breast epithelial cell line

MOD mean optical density

MTT 3-(4,5-Dimethylthiazol-2-yl)-2,5-diphenyltetrazolium bromide assay

MT1 melatonin receptor-1

MT2 melatonin receptor-2

mRNA messenger RNA

NF-kB factor nuclear kappa B

NRP2 neuropilin 2

PARP enzyme poly ADP ribose polymerase

PBS phosphate buffered saline

PLAU plasminogen activator, urokinase

p21 cyclin-dependent kinase inhibitor 1

p53 tumor protein

RNA ribonucleic acid

PKA protein kinase $\mathrm{A}$

PKC protein kinase $\mathrm{C}$

RT-PCR reverse transcription polymerase chain reaction

SFB fetal bovine serum

siRNA small interfering RNA

TNFR1 tumor necrosis factor receptor 1

TNFRII tumor necrosis factor receptor superfamily II

VEGF-A endothelial growth factor

VEGFRs receptors for vascular endothelial growth factor

XIAP X-linked inhibitor of apoptosis protein inflammatory effects associated with the IL-17 family, IL-17E (also known as IL-25) appears to be a unique pleiotropic cytokine that engages a systemic Th2-like response with tissue-specific immunological and pathological changes $[21,22]$. These changes include, but are not limited to, expression of IL-4, 5 and 13 . Thus, overexpression of IL-25 results in profound alterations in the immune system [22].

IL-25 is secreted by non-malignant mammary epithelial cells and referred to as anti-tumoral cytokine [26]. Anti-inflammatory effects have been associated with IL-25 in both in vitro and in vivo studies [21]; besides, this cytokine can induce breast cancer cell apoptosis when its receptor IL-25R (also called IL-17RB), which is composed of IL-17RB and IL-17RA heterodimer [26,27], is available on the target cell.

Furuta et al. [26] observed that another ligand, IL-17B, competes for the same receptor site of IL-25 in malignant tissues, which contributes to tumorigenic potential. IL-17B was reported to bind to IL-17RB with an affinity of $7.6 \mathrm{nM}$, while IL-25 binds to IL-17RB with an affinity in the range of 1.1-1.4 nM. The IL-17RB/IL-17B transduces pro-survival signaling, and their combined expression has been associated with poor prognosis in breast cancer patients [27].

No studies have previous addressed whether melatonin in combination with IL-25 could be a better strategy to target breast cancer cells. Here we explore the therapeutic potential of such a combinatory approach by assessing the effect of melatonin, IL-25, and IL-17B gene silencing, alone or in combination, on cell viability, differential mRNA and protein expression of apoptosis and angiogenesis mediators in malignant human breast cells.

\section{Materials and methods}

\subsection{Reagents and antibodies}

Melatonin was obtained from Sigma-Aldrich (St. Louis, MO, USA). Purified IL-25 was from ProSpec (East Brunswick, NJ, USA). Primary antibodies included: cleaved caspase-3 (Sigma-Aldrich, St. Louis, MO, USA), IL17RB and VEGF-A (both from Santa Cruz Biotechnology, Dallas, TX, USA).

\subsection{Cell lines culture}

Triple negative (MDA-MB-231) [American Type Culture Collection (ATCC), Manassas, VA, USA] and estrogen receptor (ER) positive (MCF-7) (ATCC, Manassas, VA, USA) human breast cancer cell lines, purchased from the ATCC, were cultured in $75 \mathrm{~cm}^{2}$ culture flasks (Sarstedt, Nümbrecht, Germany) with Dulbecco's modified Eagle's medium (DMEM) (Cultilab, Campinas, SP, Brazil) supplemented with 10\% fetal bovine serum (FBS) (Cultilab, Campinas, SP, Brazil), penicillin $(100 \mathrm{IU} / \mathrm{mL})$ and streptomycin $(100 \mathrm{mg} / \mathrm{mL})$ (Sigma-Aldrich, St. Louis, $\mathrm{MO}, \mathrm{USA}$ ) in a humidified incubator at $5.0 \% \mathrm{CO}_{2}$ at $37{ }^{\circ} \mathrm{C}$ until they were $80-90 \%$ confluent.

The human non-tumorigenic breast epithelial cell line (MCF-10A) (ATCC, Manassas, VA, USA), purchased from the ATCC, was cultured in 1:1 DMEM: Ham's F-12 (Cultilab, Campinas, SP, Brazil) media supplemented with $5 \%$ donor equine serum (Thermo Fisher Scientific, Waltham, MA, USA), epidermal growth factor $(20 \mathrm{ng} / \mathrm{mL}$ ) (Sigma-Aldrich, St. Louis, MO, USA), hydrocortisone (500 ng/mL) (Sigma-Aldrich, St. Louis, MO, USA), insulin $(0.01 \mathrm{mg} / \mathrm{mL})$ (Sigma-Aldrich, St. Louis, MO, USA), cholera toxin (100 ng/mL) (Sigma-Aldrich, St. Louis, MO, USA), penicillin $(100 \mathrm{IU} / \mathrm{mL})$ and streptomycin $(100 \mu \mathrm{g} / \mathrm{mL})$ (Sigma-Aldrich, St. Louis, MO, USA) in a humidified incubator at $5.0 \% \mathrm{CO}_{2}$ at $37{ }^{\circ} \mathrm{C}$ until they were $80-90 \%$ confluent.

\subsection{Three-dimensional (3D) Matrigel culture assay}

MDA-MB-231 and MCF-7 cells were maintained under standard culture conditions as aforementioned. Subconfluent monolayers were trypsinized in a solution of $0.05 \%$ Trypsin-EDTA, washed once with DMEM plus $10 \%$ FBS, and resuspended in assay media at a density of 
$3.5 \times 10^{4}$ cells/mL. Assay media consisted of Basal Human Mammary Epithelial Cell (HuMEC) medium supplemented with the HuMEC Supplement Kit (both from Gibco ${ }^{\circledR}$ - Life Technologies, Eugene, OR, USA) and $2 \%$ Matrigel ${ }^{\circledR}$ (Becton Dickinson, Franklin Lakes, NJ, USA). Five hundred microliters of the cell suspension were plated on individual wells of 8-well chamber slides (Sarsted, Newton, NC, USA) previously covered with a 1-mm thick layer of laminin-rich extracellular matrix. The cells were maintained in a humidified incubator at $5 \% \mathrm{CO}_{2}$ and $37{ }^{\circ} \mathrm{C}$ for eight days until the formation of established 3D structures, with treatments replenished every two days $(48 \mathrm{~h})$ ( $1 \mathrm{mM}$ of melatonin, $1 \mathrm{ng} / \mathrm{mL}$ of IL-25, $10 \mathrm{nM}$ of silL-17B, combined treatments and specific control groups). These concentrations were previously selected based on results from the cell viability assay (method described below). The apoptosis of 3D structures was analyzed using immunofluorescence and confocal microscopy, as indicated below.

2.4. Cell viability assessment by 3-(4,5-Dimethylthiazol-2-yl)-2,5-diphenyltetrazolium bromide (MTT) assay

For MTT assay, individual wells of $0.31 \mathrm{~cm}^{2}$ (96-well plate) were inoculated with $100 \mu \mathrm{L}$ of regular growth medium containing $5 \times 10^{4}$ cells and incubated in this media overnight, after which the media was changed to $2.0 \% \mathrm{FBS}$, containing increasing concentrations of melatonin ( $0.00001 \mathrm{mM}, 0.0001 \mathrm{mM}, 0.001 \mathrm{mM}, 0.01 \mathrm{mM}, 0.1 \mathrm{mM}$ and $1 \mathrm{mM}$ ) and different concentrations of purified IL-25 ( $1 \mathrm{ng} / \mathrm{mL}, 10 \mathrm{ng} / \mathrm{mL}$ and $50 \mathrm{ng} / \mathrm{mL}$ ). Control wells, corresponding to $0 \mathrm{ng} / \mathrm{mL}$ of either treatment, contained the highest concentration of the vehicle for the corresponding treatment, which was $1 \%$ dimethylsulfoxide (DMSO) (Sigma-Aldrich, St. Louis, MO, USA) for melatonin, and $0.001 \%$ e-pure water for IL-25. Following $48 \mathrm{~h}$ of the aforementioned treatments, $10 \mu \mathrm{L}$ of MTT solution from the Vibrant MTT Cell Proliferation Assay Kit (Invitrogen - Life Technologies, Eugene, OR, USA) was added to each well and the plates were incubated at $37^{\circ} \mathrm{C}$ for an additional $4 \mathrm{~h}$. To solubilize the MTT formazan crystals, the cells were incubated with $50 \mu \mathrm{L}$ of DMSO (100\%) and then incubated again at $37^{\circ} \mathrm{C}$ for $10 \mathrm{~min}$. Absorbance was measured at $540 \mathrm{~nm}$ using an ELISA plate reader (Thermo Fisher Scientific - Waltham, MA USA). Medium alone was used as a blank and the corresponding optical density was subtracted from the samples. Cell viability (\%) was calculated for all groups relative to control samples. All treatments were done in triplicate.

\subsection{Gene silencing of interleukin-17B}

For IL-17B gene silencing, four different siRNA were initially tested (SI00106127, SI00106134, SI02640652 and SI02640659) (ProSpec, East Brunswick, NJ, USA), selected from preserved gene regions and thermodynamic stability according to inventoried assay (Qiagen, Valencia, CA, USA). Individual wells of $1.88 \mathrm{~cm}^{2}$ (24-well plate) were inoculated with $500 \mu \mathrm{L}$ of normal growth medium containing $8 \times 10^{4}$ cells. Subsequently, cells were transfected using siRNA Human/Mouse Starter Kit (Qiagen, Valencia, CA, USA), which included the positive control MAPK-1 siRNA (Qiagen, Valencia, CA, USA), a siScramble negative control (Qiagen, Valencia, CA, USA) and the Gene Kit Solution targeting silL-17B (Cat No. 1027416 - Qiagen, Valencia, CA, USA), all at $10 \mathrm{nM}$ in a $0.5 \%$ HiPerfect solution (Qiagen, Valencia, CA, USA). Cells were incubated with these reagents for $48 \mathrm{~h}$, after which total cellular RNA was isolated using the Trizol method (Invitrogen - Life Technologies, Eugene, OR, USA) and purified using the RNeasy Kit extraction columns (Qiagen, Valencia, CA, USA).

\subsection{Relative $m R N A$ quantification by real-time ( $q R T-P C R$ )}

The concentration of RNA from each sample was determined using a NanoDrop 2000 Spectrophotometer (Thermo Fisher Scientific - Waltham, MA USA). cDNA was obtained by RT-PCR (Reverse TranscriptasePolymerase Chain Reaction) using the High Capacity cDNA Kit (Applied Biosystems, Foster City, CA, USA).
The qRT-PCR reaction was performed to assess the efficiency of gene silencing of IL-17B, as well as the effect of the treatment on caspase-3 and VEGF-A levels, using a StepOne Plus Real Time PCR System (Applied Biosystems, Foster City, CA, USA). Specific primers included: IL-17B sense (5' GCAGCTGTGGATGTCCAACA 3') antisense (5' GGGTCGTGGT TGATGCTGTAG $3^{\prime}$ ) and MAPK-1 - sense (5' TCCAACCTGCTGCTCAACAC $3^{\prime}$ ) antisense ( $5^{\prime}$ TCATGGTCTGGATCTGCAACA $3^{\prime}$ ), inventoried TaqMan assays caspase-3 (Hs0023487_m1), VEGFA (Hs00900055_m1), and the housekeeping genes beta-actin (ACTB; 4333762F) and glyceraldehyde3-phosphate dehydrogenase (GAPDH; 4333764F), all at a concentration of $100 \mathrm{ng}$ for each cDNA sample.

The amplification was performed in cycles at $95^{\circ} \mathrm{C}$ for $10 \mathrm{~min}$, followed by 40 cycles at $95{ }^{\circ} \mathrm{C}$ for $15 \mathrm{~s}$ and $60^{\circ} \mathrm{C}$ for one minute. The samples were tested in triplicate and each experiment included a negative control. The value of the relative expression of the genes of interest was determined with DataAssist 3.0 software (Applied Biosystems, Foster City, CA, USA) by $\Delta \Delta \mathrm{Ct}$ method [28]. The RQ value for each respective control group was initially established as 1.0 au to assess relative changes. The analysis was ultimately performed on values converted to a logarithmic scale, which sets the expression value for control groups as 0 (zero). Treatments were interpreted as underexpressed or overexpressed relative to controls.

\subsection{Immunofluorescence staining}

Previously treated 3D structures grown on matrigel and treated monolayer cells were washed once with PBS, fixed in $4.0 \%$ paraformaldehyde solution in PBS for 20 min at room temperature, added a 0.5\% Triton in PBS solution and blocked with 10\% donkey serum solution for $1 \mathrm{~h}$ at room temperature. The specific primary antibodies were then added and incubated overnight at $4{ }^{\circ} \mathrm{C}$. After washing three times with immunofluorescence (IF) buffer (0.1\% FSB, $0.2 \%$ triton and $0.05 \%$ Tween 20$)$, a secondary Alexa Fluor 488 anti-rabbit IgG (Sigma-Aldrich, St. Louis, MO, USA) for both cleaved caspase- 3 and VEGF-A was added per $1 \mathrm{~h}$ at room temperature. Following three time washing with IF buffer, the cells were incubated with 4',6-diamidino-2-phenylindole (DAPI) solution (Life Technologies, Eugene, OR, USA) and mounted with Prolong Gold $®$ (Life Technologies, Eugene, OR, USA). Images from 3D structures were captured and processed using a confocal microscope and associated software (ZEISS, model LSM 710, software ZEN 2010, Thornwood, NY, USA) and monolayer cells were captured and processed using a standard fluorescence microscope and associated software (OLYMPUS, model BX53, software Image-Pro Plus version 7.0, Center Valley, PA, USA).

\subsection{Evaluation of immunofluorescence staining}

For apoptosis analysis, all cleaved caspase-3 positive cells were counted in three different photomicrographs $(100 \times$ magnification $)$ per treatment group. Results were quantified as percent of apoptotic cells in monolayer and 3D structures. The number of cleaved caspase- 3 positive cells was normalized to the area of the photomicrography.

IL-17RB and VEGF-A proteins were quantified according to JardimPerassi et al. [29]. In summary, three different photomicrographs were taken at $100 \times$ magnification and the intensity of the staining was quantified by Image J Software (NIH, Bethesda, MD, USA). Each photograph was divided into four quadrants, and 20 spots (small circular ROI) were randomly selected (avoiding the nucleus) in each photomicrograph. A negative control section of the corresponding staining was used for measuring background activity. The values were obtained in arbitrary units (au) and showed the mean optical density (MOD) to each sample.

\subsection{Protein extraction}

In order to reaffirm melatonin action in apoptosis pathway in triple negative breast cancer cells, we performed a membrane array analysis in MDA-MB-231 cells. Cells were plated in individual wells of $1.88 \mathrm{~cm}^{2}$ 
(24-well plate) at a $0.5 \times 10^{6}$ cell density and inoculated with $500 \mu \mathrm{L}$ of normal growth medium overnight. Thereafter, we treated cells with or without $1 \mathrm{mM}$ of melatonin for $48 \mathrm{~h}$ and performed protein extraction of adherent and supernatant cells. Cells were washed in ice-cold PBS and lysed with MILLIPLEX® MAP lysis buffer supplemented with $1 \mathrm{mM}$ of phosphatase inhibitor cocktail (Sigma-Aldrich, St. Louis, MO, EUA) and 1:10 of protease inhibitor (Sigma-Aldrich, St. Louis, MO, EUA). After incubation for $30 \mathrm{~min}$ with intermittent vortexing, the cell lysate was centrifuged and the proteins collected on supernatant. Concomitantly the supernatant medium was collected and we used ultrafiltration (Amicon ${ }^{\circledR}$, EMD Millipore, Billerica, MA) to concentrate the proteins. The supernatant was included in columns containing filter of $3 \mathrm{kDa}$ and centrifuged. Larger proteins that were retained in filter were extracted and subsequently quantified.

Protein extract was quantified by the bicinchoninic acid (BCA) protein assay kit (PIERCE - Thermo Scientific - Thermo Fisher Scientific, Waltham, MA, USA).

\subsection{Membrane array}

The membrane Human Apoptosis Array C1 (RayBiotech, Norcross, GA, EUA) (Table 1 ) was incubated with $2 \mathrm{~mL}$ of $1 \times$ blocking solution buffer (RayBiotech, Norcross, GA, EUA) for $30 \mathrm{~min}$. Treated and control samples were added at a concentration of $600 \mu \mathrm{g}(300 \mu \mathrm{g}$ of lysate cells and $300 \mu \mathrm{g}$ of supernatant cells) and incubated on the membrane at $4{ }^{\circ} \mathrm{C}$ overnight. Next, the membrane was washed three times with wash buffer $1 \times$ (RayBio I, RayBiotech, Norcross, GA, EUA) for five minutes each. Biotin conjugate anti-cytokines (RayBiotech, Norcross, GA, EUA) were added and the samples were incubated at $4^{\circ}$ overnight. The membrane was washed again and then incubated with horseradish peroxidase (HRP) streptavidin $1000 \times$ (RayBiotech, Norcross, GA, EUA) solution at $4{ }^{\circ} \mathrm{C}$ overnight. Finally, the membrane was washed and incubated with detection solution (RayBiotech, Norcross, GA, EUA) for two minutes and exposed to ChemiDoc system (BioRad, Hercules, CA, EUA).

Optical density reference to protein expression was normalized with positive control and quantification was performed using Image Software (NIH, Bethesda, MD, USA) as image analyzer. The values were obtained in arbitrary units and represented as the MOD to each sample. All samples were included in duplicate plus positive and negative membrane controls.

\subsection{Statistical analysis}

All data was expressed as mean \pm standard error of mean (SEM). All statistical analyses were done using GraphPad Prism 4 (San Diego, CA, USA). Raw data was initially subjected to descriptive analysis to determine the normal range. Normal range data was analyzed by two-way ANOVA, followed by Bonferroni test for MTT results and Student's $t$ test was used for other analyses. A p-value $\leq 0.05$ was considered significant.

\section{Results}

3.1. Melatonin and IL-25 reduce viability of breast cancer cells but do not affect non-transformed MCF-10A cells

Breast cancer cell lines and MCF-10A were subjected to MTT cell viability testing, after being treated with IL-25 (breast cancer cells) or melatonin + IL-25 (MCF-10A). Jardim-Perassi et al. [29,30] previously showed that the MDA-MB-231 and MCF-7 cells were sensitive to $1 \mathrm{mM}$ of melatonin after $24 \mathrm{~h}$ of incubation, showing a statistically significant reduction in cell viability compared to control groups $(\mathrm{p}<0.05)$. Similar results were found by Borin et al. [31] following $48 \mathrm{~h}$ of treatment. As the $1 \mathrm{mM}$ concentration showed a significant reduction of viability, it was adopted as the standard dose for the current study.
Table 1

Human apoptosis array C1 (RayBiotech) for analysis of protein expression profile of MDAMB-231 cells after melatonin treatment.

\begin{tabular}{llll}
\hline Apoptotic factors & Melatonin treatment & Apoptotic factors & Melatonin treatment \\
\hline BAD & $\mathrm{ns}$ & BAX & $\mathrm{ns}$ \\
CD40 & $\mathrm{ns}$ & BCL-2 & $\mathrm{ns}$ \\
CD40 LIGAND & $\mathrm{ns}$ & BCL-W & $\mathrm{ns}$ \\
BIRC-3 & $\mathrm{ns}$ & BID & $\mathrm{ns}$ \\
CYTO C & $\uparrow \mathrm{p}=0.04$ & BIM & $\mathrm{ns}$ \\
DR6 & $\uparrow \mathrm{p}=0.02$ & CASPASE-3 & $\downarrow \mathrm{p}=0.04$ \\
FAS & $\mathrm{ns}$ & CASPASE-8 & $\mathrm{ns}$ \\
FAS LIGAND & $\mathrm{ns}$ & HSP27 & $\mathrm{ns}$ \\
IGFBP-1 & $\mathrm{ns}$ & HSP60 & $\mathrm{ns}$ \\
IGFBP-2 & $\mathrm{ns}$ & HSP70 & $\mathrm{ns}$ \\
IGFBP-3 & $\uparrow \mathrm{p}=0.03$ & hTRA & $\uparrow \mathrm{p}=0.02$ \\
IGFBP-4 & $\mathrm{ns}$ & IGF-1 & $\uparrow \mathrm{p}=0.02$ \\
IGFBP-5 & $\uparrow \mathrm{p}=0.01$ & IGF-2 & $\mathrm{ns}$ \\
IGFBP-6 & $\uparrow \mathrm{p}=0.01$ & LIVIN & $\uparrow \mathrm{p}=0.04$ \\
IGF-1R & $\uparrow \mathrm{p}=0.05$ & P21 & $\uparrow \mathrm{p}=0.03$ \\
TNF-RII & $\uparrow \mathrm{p}=0.04$ & P27 & $\mathrm{ns}$ \\
TNF- $\alpha$ & $\mathrm{ns}$ & P53 & $\uparrow \mathrm{p}=0.04$ \\
TNF- $\beta$ & $\mathrm{ns}$ & SMAC & $\mathrm{ns}$ \\
TRAIL-R1 & $\mathrm{ns}$ & SURVININ & $\mathrm{ns}$ \\
TRAIL-R2 & $\mathrm{ns}$ & TNF-RI & $\mathrm{ns}$ \\
TRAIL-R3 & $\mathrm{ns}$ & XIAP & $\uparrow \mathrm{p}=0.04$ \\
TRAIL-R4 & $\mathrm{ns}$ & & \\
\hline
\end{tabular}

BAD: Bcl-2-antagonist of cell death; BAX: Bcl-2-associated X protein; BCL-2: B-cell lymphoma 2; BCL-W: Bcl-2-like protein 2; BID: $\mathrm{BH} 3$ interacting-domain death agonist; BIM: Bisindolylmaleimide-based protein kinase C (PKC) inhibitors; BIRC-3: Baculoviral IAP repeat-containing protein 3; CASPASE-3: Cysteine-aspartic acid protease 3; CASPASE-8: Cysteine-aspartic acid protease 8; CD40: Cluster of differentiation 40; CD40 LIGAND: Cluster of differentiation 40 ligand; CYTO C: Cytochrome c; DR6:Death receptor 6; FAS: First apoptosis signal; FAS LIGAND: First apoptosis signal ligand; HSP27: Heat shock protein 27; HSP60: Heat shock protein 60; HSP70: Heat shock protein 70; hTRA: High-temperature requirement A serine peptidase; IGF-1: Insulin-like growth factor 1; IGF-2: Insulin-like growth factor 2; IGFBP-1: Insulin-like growth factor-binding protein 1; IGFBP-2: Insulinlike growth factor-binding protein 2; IGFBP-3: Insulin-like growth factor-binding protein 3; IGFBP-4: Insulin-like growth factor-binding protein 4; IGFBP-5: Insulin-like growth factor-binding protein 5; IGFBP-6: Insulin-like growth factor-binding protein 6; IGF-1R: Insulin-like growth factor receptor 1; Livin; P21: Cyclin-dependent kinase inhibitor 1; P27: Cyclin-dependent kinase inhibitor 1B; P53: Tumor protein p53; SMAC:Second mitochondria-derived activator of caspases; Survinin; TNF- $\alpha$ : Tumor necrosis factor alpha; TNF- $\beta$ : Tumor necrosis factor beta; TNF-RI: Tumor necrosis factor receptor 1; TNF-RII: Tumor necrosis factor receptor 2; TRAIL-R1: TNF-related apoptosis-inducing ligand receptor 1 ; TRAIL-R2: TNF-related apoptosis-inducing ligand receptor 2; TRAIL-R3: TNF-related apoptosis-inducing ligand receptor 3; TRAIL-R4: TNF-related apoptosis-inducing ligand receptor 4; XIAP: X-linked inhibitor of apoptosis protein. All antibodies are prepared in duplicate. ns: no significant.

Cell viability was tested with IL-25 at 1,10 , and $50 \mathrm{ng} / \mathrm{mL}$ for $48 \mathrm{~h}$, and there was a reduction in cell viability in both breast cancer cell lines. For MDA-MB-231 cells, a biphasic effect was observed, with $1 \mathrm{ng} / \mathrm{mL}$ and $50 \mathrm{ng} / \mathrm{mL}$ of IL-25 causing a significant 26\% - 27\% reduction in viability compared to the control group $(74.0 \pm 10.2 \%$ and $72.5 \pm 8.5 \%$, respectively; $\mathrm{p}<0.05)$. For MCF-7 cells, the lowest dose of $1 \mathrm{ng} / \mathrm{mL}$ of IL-25 significantly reduced cell viability by $61 \%(39.0 \pm 8.9 \%$; $<<0.05)$ (Fig. $1 \mathrm{~A}$ and B).

Neither melatonin nor IL-25 treatments caused a significant reduction in viability compared to control in MCF-10A cells, when the effective doses for MDA-MB-231 and MCF-7 cells were chosen ( $p>0.05$ ) (Fig. 1C). These results suggest that melatonin and IL-25 preferentially target the transformed cells.

\subsection{Effective IL-17B silencing}

In order to test our hypothesis that a reduction in IL-17B level may lead to increased tumor cell apoptosis by enhancing IL-25 binding to the IL-17RB receptor, IL-17B gene silencing was performed, as there is no specific inhibitor for this interleukin. Silencing of the positive control, MAPK-1, was carried out to optimize the concentration and incubation period of the transient transfection. The positive control was effective at $10 \mathrm{nM}$ in both breast cancer cell lines with $74.0 \%$ for MDA-MB-231 cells and $67.0 \%$ for MCF-7 cells 48 h after transfection (data not 

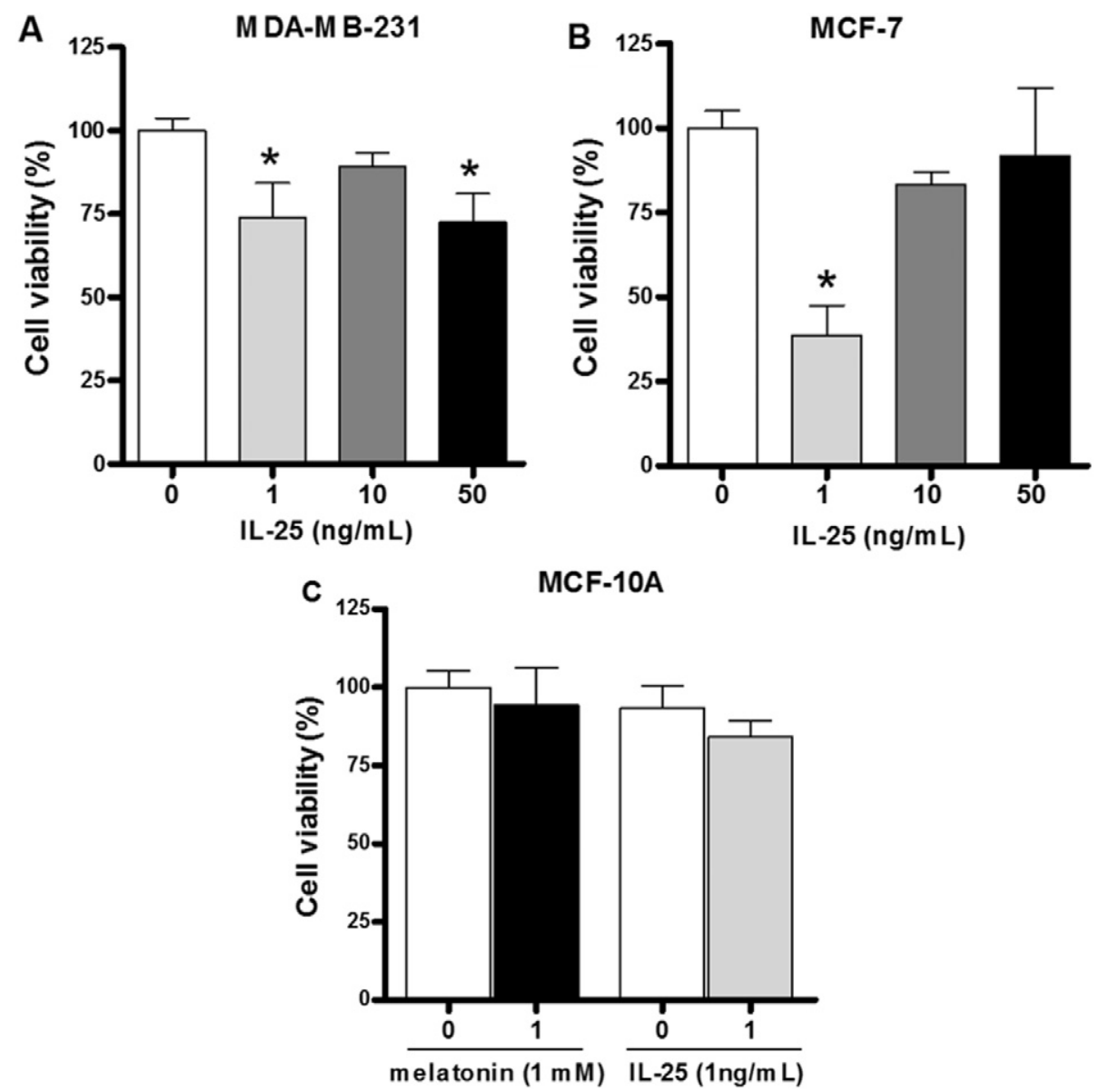

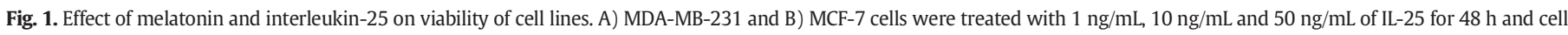

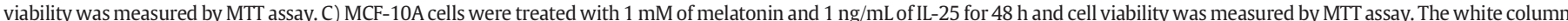

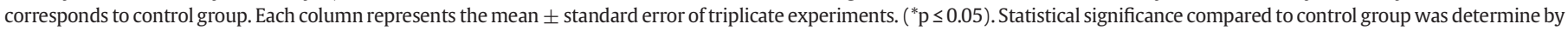
ANOVA followed by Bonferroni test.

shown). siRNA \#2 and \#3 were effective for IL-17B silencing for MDAMB-231 cells with the best silencing (44.0\%) obtained with silL-17B \#2 (Fig. 2A). For MCF-7 cells, gene silencing was effective for siRNA \#2, \#3 and \#4, with $66.0 \%$ of silencing for silL-17B \#2 (Fig. 2B).

\subsection{Induction of apoptosis by melatonin, IL-25 and silL-17B treatment of monolayer and three-dimensional breast cancer cell cultures}

To test the hypothesis that IL-25 signaling engagement added to melatonin enhances breast cancer cell apoptosis, breast cancer cell lines were cultured with $1 \mathrm{mM}$ of melatonin, $1 \mathrm{ng} / \mathrm{mL}$ of IL-25 and $10 \mathrm{nM}$ of

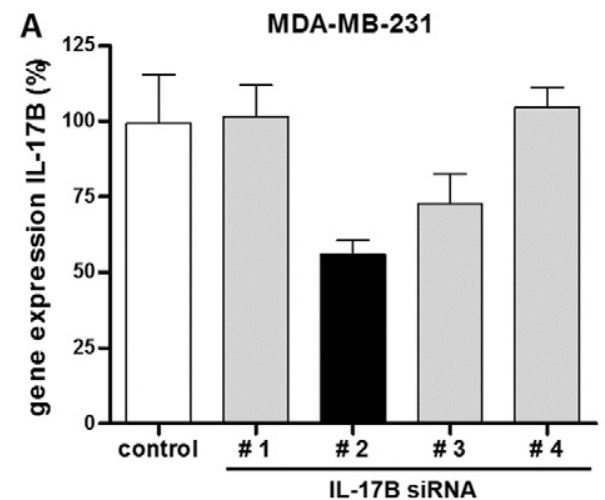

silL-17B \#2 as well as their respective vehicles, for 48 h. Caspase-3 mRNA expression was evaluated by real-time PCR, while cleaved caspase- 3 was examined by immunofluorescence (see Methods for details).

The three treatments separated and in combination, were effective at increasing the caspase-3 gene expression in MDA-MB-231 cells. The difference in caspase- 3 expression between control and treated cells was $0.3 \mathrm{au}( \pm 0.01 \mathrm{au} ; \mathrm{p}<0.0001)$ with melatonin, $0.3 \mathrm{au}( \pm 0.02 \mathrm{au} ; \mathrm{p}=$ 0.0002 ) with IL-25, $0.2 \mathrm{au}( \pm 0.01 \mathrm{au} ; \mathrm{p}=0.0001)$ with silL-17B, and 0.4 au $( \pm 0.03$ au; $p=0.0002)$ after combined treatment. Furthermore, MDA-MB-231 cells treated for $48 \mathrm{~h}$ showed a $\sim$ 3-fold higher average of positive apoptotic cells compared to their control group for each

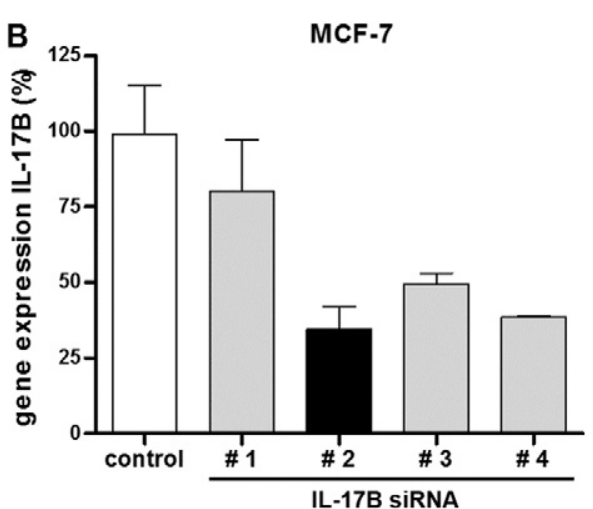

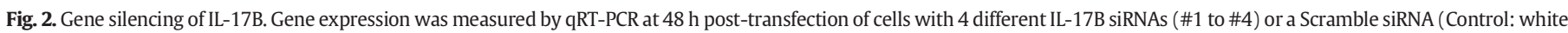
colum). A) MDA-MB-231 cells showed 44\% gene silencing with $10 \mathrm{nM}$ of silL-17B \#2. B) MCF-7 cells showed 66\% gene silencing with $10 \mathrm{nM}$ of silL-17B \#2. 
treatment ( $\mathrm{p}<0.05$ in all cases), as determined by cleaved caspase- 3 immunofluorescence. The combined treatments did not further increase apoptosis compared to individual treatments (Fig. 3).

Similarly, melatonin, IL-25 and silL-17B treatments for $48 \mathrm{~h}$, alone and combined, were effective in increasing the caspase- 3 gene expression in MCF-7 cells. The difference in caspase- 3 expression between control and treated cells was $1.0 \mathrm{au}( \pm 0.05 \mathrm{au} ; \mathrm{p}=0.002)$ for melatonin, $0.3 \mathrm{au}$ ( $\pm 0.04 \mathrm{au} ; \mathrm{p}=0.01$ ) for IL-25, $0.8 \mathrm{au}( \pm 0.1 \mathrm{au} ; \mathrm{p}=0.01)$ for silL-17B, and $1.4 \mathrm{au}( \pm 0.2 \mathrm{au} ; \mathrm{p}=0.002)$ for combined treatments. The average percent of apoptotic cells after $48 \mathrm{~h}$ of individual treatments was $~ 3-4$ times higher than their respective control groups $(p<0.05)$. Importantly, for MCF-7 cells, the combined treatment showed pro-apoptotic advantage compared to melatonin alone, as it resulted in an average 4.4 fold enhancement of the percentage of apoptotic cells, as compared to the 3 fold enhancement observed with melatonin alone (Fig. 4).

As an alternative to classical in vitro studies with cells grown as monolayers, the 3D culture on reconstituted basement membrane mimics tissue architecture in vivo, possibly predicting better cellular response in actual tumors [32]. 3D culture permits cells to explore the three dimensions of the space thereby increasing cell-cell interactions, as well as interactions with the microenvironment [32]. Thus, we aimed to characterize the increased expression of cleaved caspase- 3 in 3D structures of breast cancer cells.
Positive nuclear staining of cleaved caspase- 3 in different sequential plane images of MDA-MB-231 and MCF-7 cells was observed in all groups, including controls (Fig. $5 \mathrm{~A}$ and $\mathrm{B}$ ). Compare to respective control group, treatment with $1 \mathrm{mM}$ of melatonin enhanced the proportion of apoptotic cells by $31 \%$ for MDA-MB-231, and by $24 \%$ for MCF-7 ( $\mathrm{p}=$ $0.05 ; \mathrm{p}=0.002$, respectively). IL-25 treatment enhanced apoptotic cells by $20 \%$ for MDA-MB-231, and by $26 \%$ for MCF-7 ( $p=0.04 ; \mathrm{p}=$ 0.01 , respectively). silL-17B was more effective at enhancing the proportion of apoptotic cells: 68\% for MDA-MB-231 and 74\% for MCF-7 (p < $0.0001 ; \mathrm{p}<0.0001$, respectively). Combined treatments did not increase the percentage of apoptotic cells in MDA-MB-231 3D structures, while it has a similar effect to that of melatonin alone in MCF-7 3D structures (30\% combined treatments versus $11 \%$ control group; $\mathrm{p}=0.01$ ) (Fig. $5 \mathrm{C}$ and $\mathrm{D})$.

3.4. Melatonin modulates expression of apoptosis mediators in MDA-MB231 cells

Apoptosis-associated proteins were assessed in MDA-MB-231 cells using a membrane protein array. As compared to control group, treatment with $1 \mathrm{mM}$ of melatonin for $48 \mathrm{~h}$ showed a significant increase of cytochrome c (CYTO-C), death receptor 6 (DR6), insulin-like growth factor-binding protein-3 (IGFBP-3), -5 (IGFBP-5), -6 (IGFPB-6), insulin-like growth factor-1 (IGF-1), IGF-1 receptor (IGF-1R), Livin, P21, P53,

MDA-MB-231
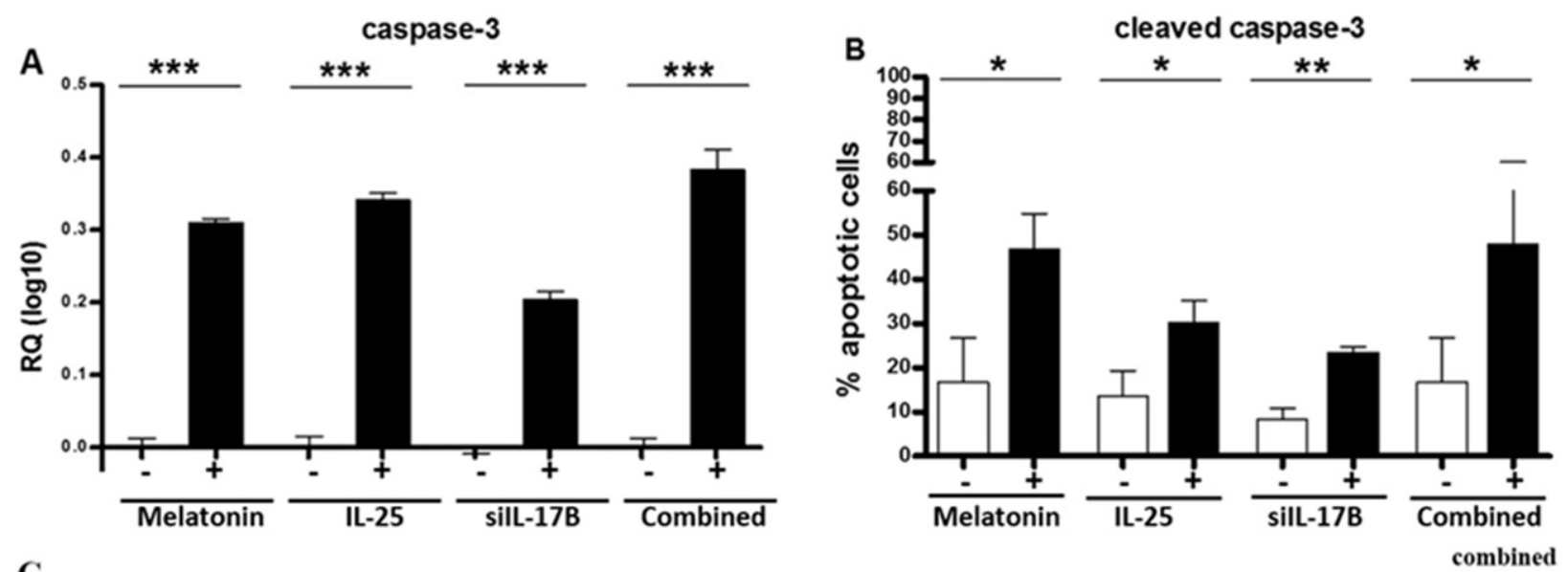

C
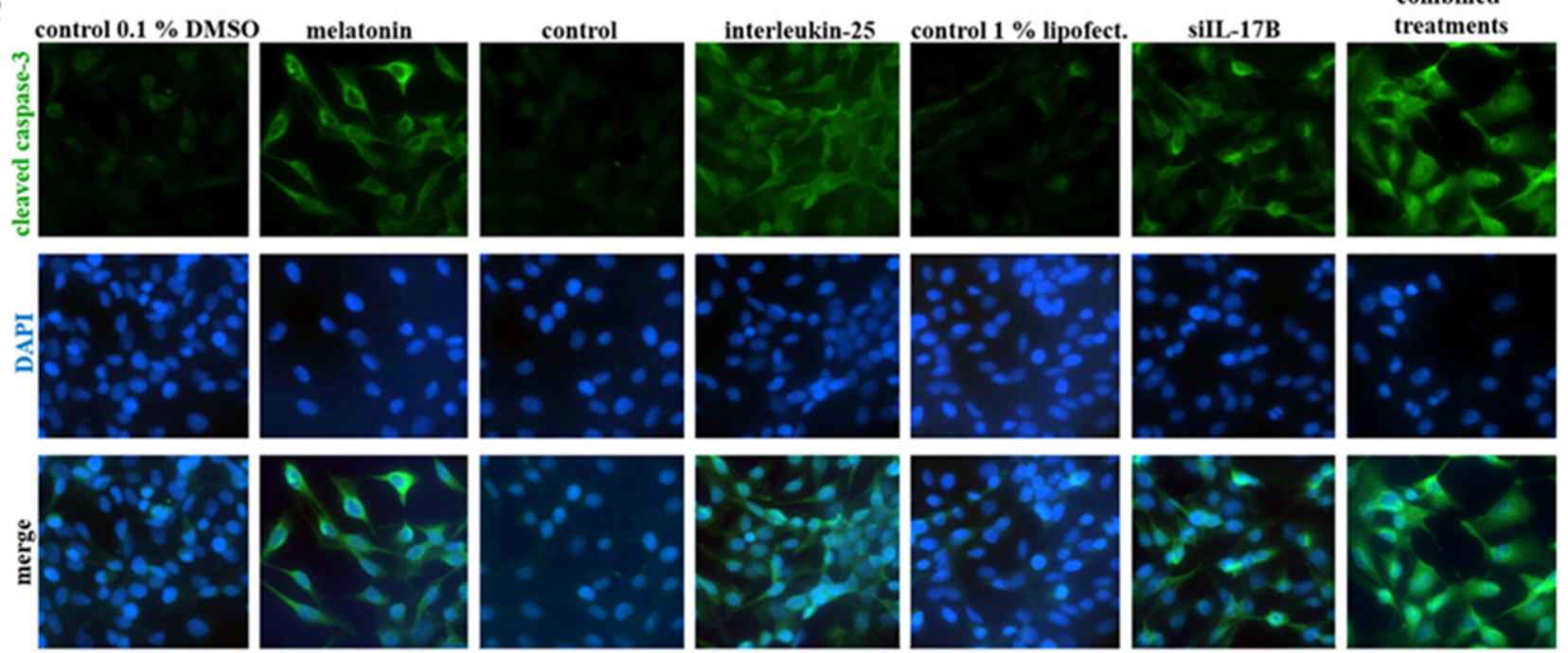

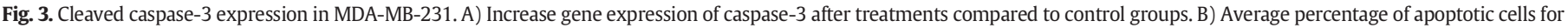

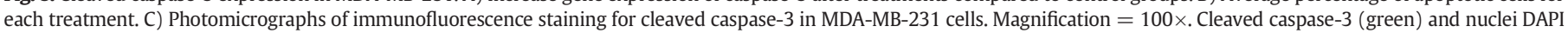
(blue). Each column represents the mean \pm standard error of triplicate experiments $\left({ }^{*} \mathrm{p} \leq 0.05\right)$. Significance was determined by Student's $t$-test. ${ }^{*} \mathrm{p}<0.01{ }^{* *} \mathrm{p}<0.001{ }^{* * *} \mathrm{p}<0.0001$. 
MCF-7
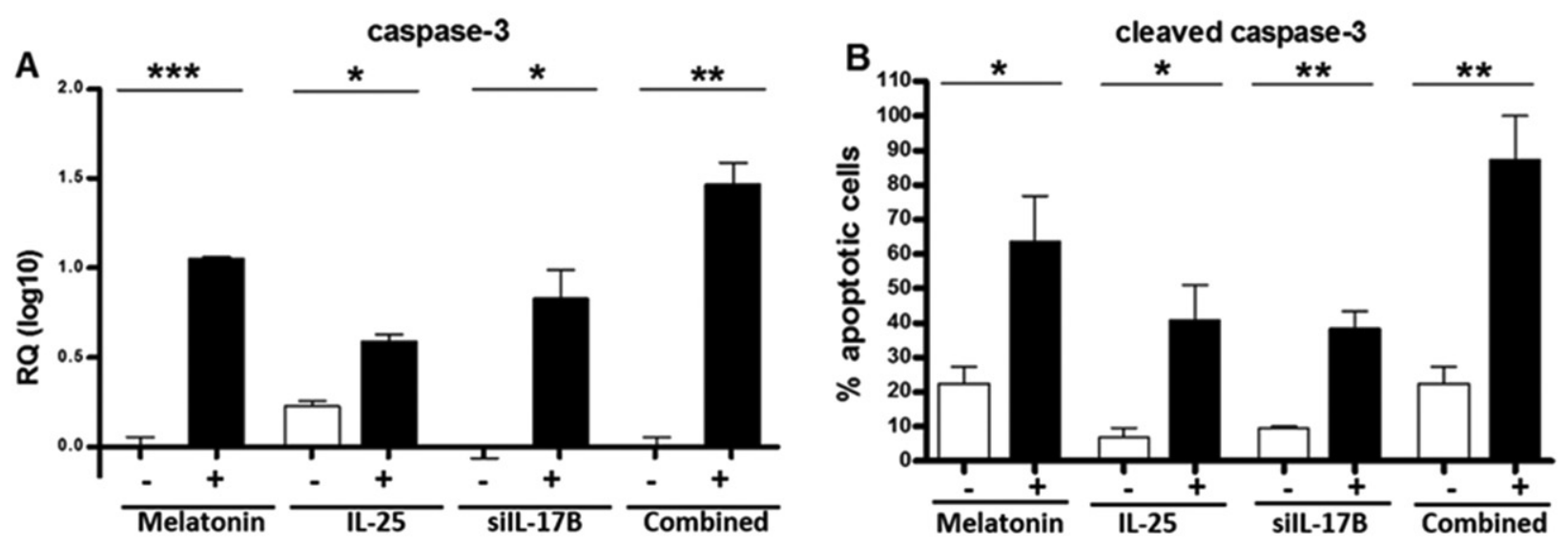

C

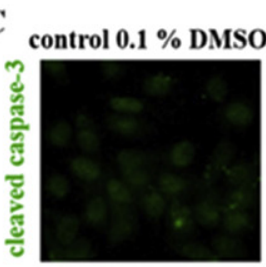

melatonin
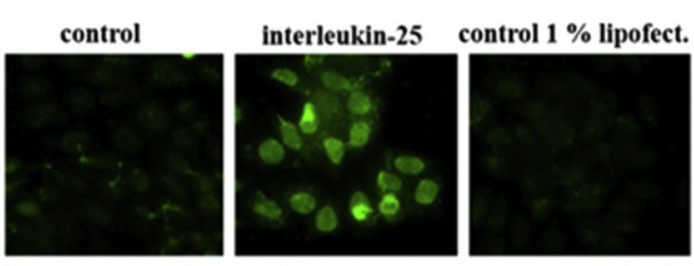

siIL-17B

combined
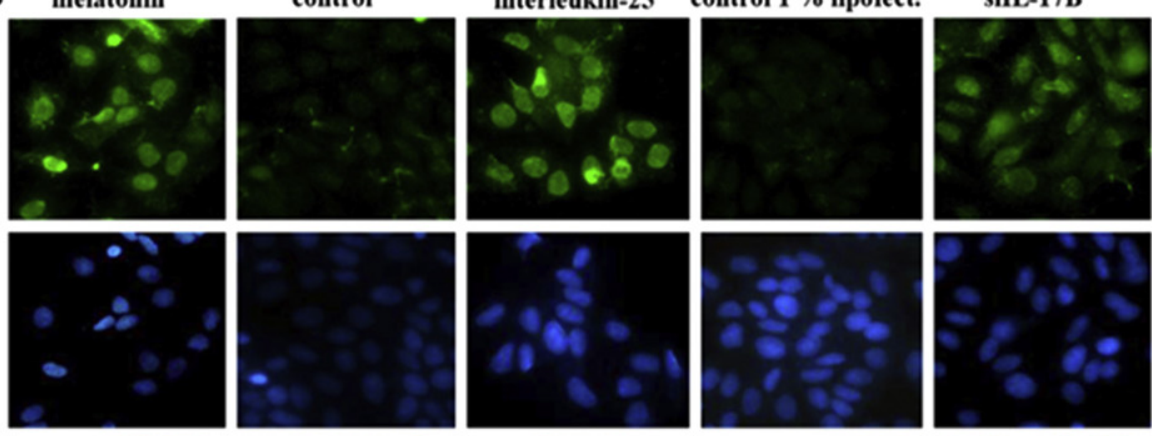

treatments
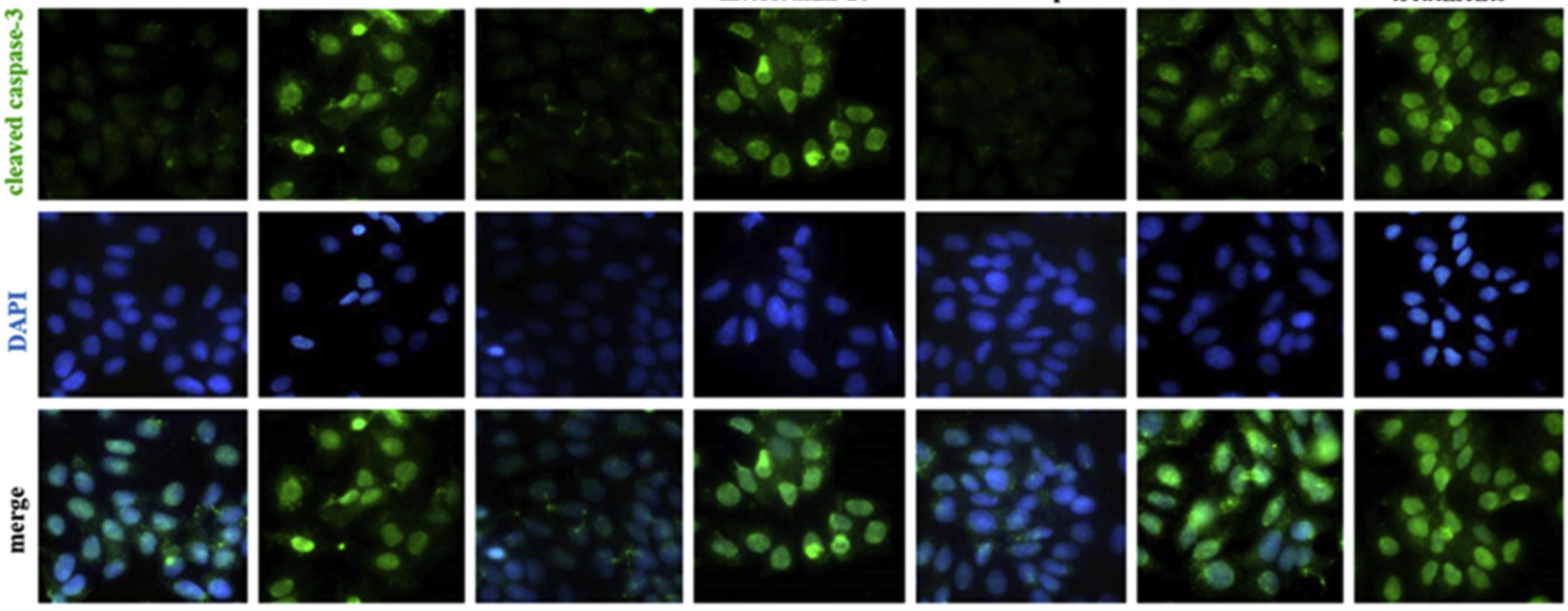

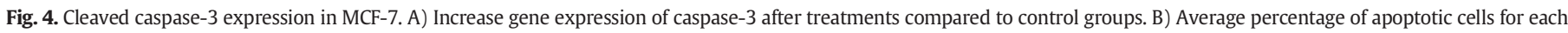

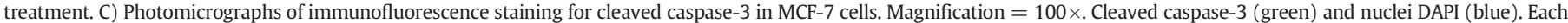
column represents the mean \pm standard error of triplicate experiments $\left({ }^{*} \mathrm{p} \leq 0.05\right)$. Significance was determined by Student's $t$-test. ${ }^{*} \mathrm{p}<0.01{ }^{* *} \mathrm{p}<0.001{ }^{* * *} \mathrm{p}<0.0001$.

tumor necrosis factor receptor II (TNFRII), apoptosis inhibitory protein X (XIAP) and high temperature required A (hTRA) $(\mathrm{p}<0.05)$. A significant reduction of caspase- 3 was also observed $(p=0.04)$ (Fig. 6$)$.

3.5. Decreased expression of VEGF after treatment with melatonin, IL-25 and silL-17B

Next, we tested the influence of $48 \mathrm{~h}$ treatment with melatonin, IL-25 and silL-17B separately or in combination, on VEGF-A mRNA and protein expression.

We observed a significant increase of VEGF-A mRNA expression in MDA-MB-231 cells after treatments with IL-25, silL-17B and when the treatments were combined. The difference in VEGF-A mRNA expression between control and treated cells with IL-25 was 0.07 au ( $\pm 0.01 \mathrm{au} ; \mathrm{p}=$ 0.007), with silL-17B treatment was $0.08 \mathrm{au}( \pm 0.01 \mathrm{au} ; \mathrm{p}=0.002)$ and after associated treatments was $0.1 \mathrm{au}( \pm 0.02 \mathrm{au} ; \mathrm{p}=0.006)$. In contrast, the protein levels of this factor were significantly reduced by treatments with melatonin ( $16.0 \pm 0.6 \mathrm{au}$, compared to control group $30.0 \pm$ $1.0 \mathrm{au} ; \mathrm{p}<0.0001$ ), IL-25 (10.7 \pm 0.3 au, compared to control group 28.2 \pm 0.8 au; $\mathrm{p}<0.0001)$, silL-17B ( $14.0 \pm 0.5$ au, compared to control group $22.0 \pm 0.5 \mathrm{au} ; \mathrm{p}<0.0001)$ and combined treatments $(21.1 \pm 0.7 \mathrm{au}$, compared to control group $30.0 \pm 1.0 \mathrm{au} ; \mathrm{p}<0.0001$ ) (Fig. 7). In comparison with all other treatments, IL-25 was the most potent at reducing
VEGF protein levels and the combined treatment was less effective than IL-25 alone (Fig. 7).

For MCF-7 cells, VEGF-A mRNA decreased after treatment with melatonin, with a difference of -0.18 au between control group ( $\pm 0.05 \mathrm{au}$; $\mathrm{p}=0.02$ ). In contrast, IL-25, silL-17B and combined treatments increased VEGF-A gene expression. The difference in VEGF-A expression between control and treated cells with IL-25 was $1.5 \mathrm{au}( \pm 0.02 \mathrm{au}, \mathrm{p}$ $<0.0001)$, silL-17B was 0.5 au $( \pm 0.01$ au, $\mathrm{p}<0.0001)$ and when treatments were combined the observed difference was 0.9 au $( \pm 0.04, \mathrm{p}<$ 0.0001 ). VEGF-A protein levels were modulated after $48 \mathrm{~h}$ of incubation, with all treatments showing a reduction after melatonin treatment (17.1 \pm 0.6 au, compared to control group $22.5 \pm 0.9 ; \mathrm{p}<0.0001)$, IL25 (14.4 $\pm 0.4 \mathrm{au}$, compared to control group $25.3 \pm 1.3 ; \mathrm{p}<0.0001)$, silL-17B (18.0 $\pm 0.7 \mathrm{au}$, compared to control group $21.1 \pm 0.8 ; \mathrm{p}=$ $0.004)$ and after combined treatments ( $15.0 \pm 0.6 \mathrm{au}$, compared to control group $22.5 \pm 0.9 ; \mathrm{p}<0.0001$ ) (Fig. 8). In comparison with all other treatments, IL-25 was the most potent at reducing VEGF protein levels and the combined treatment was not better than IL25 alone (Fig. 8).

\section{Discussion}

This study confirms previous findings that pharmacological levels of melatonin reduce cell viability of triple negative and ER-positive breast 

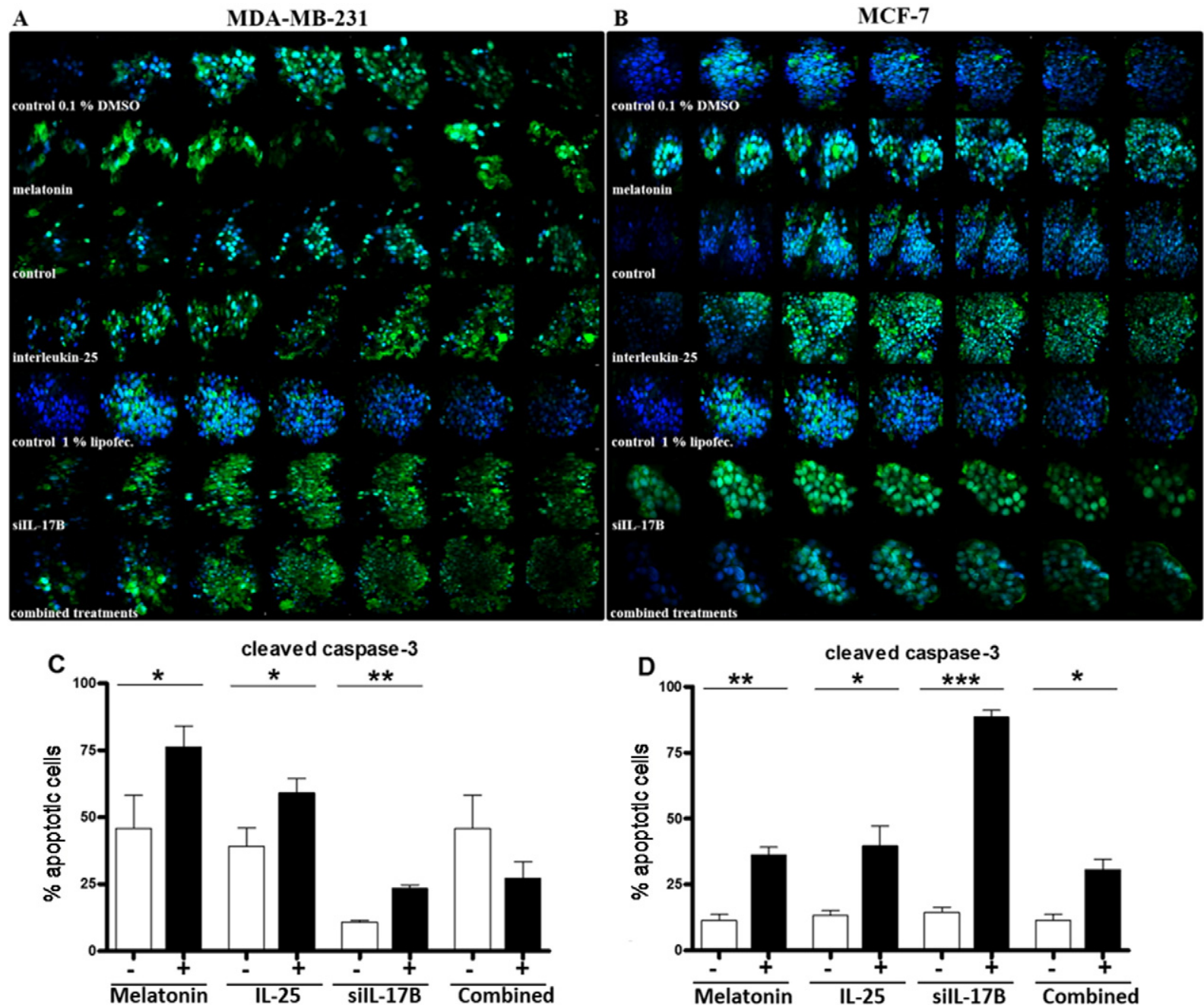

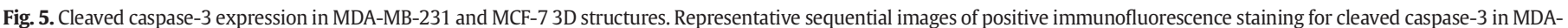

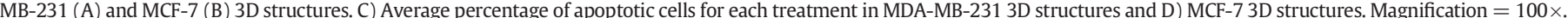
Each column represents the mean \pm standard error of triplicate experiments $\left({ }^{*} \mathrm{p} \leq 0.05\right)$. Significance was determined by Student's $t$-test. ${ }^{*} \mathrm{p}<0.01{ }^{* *} \mathrm{p}<0.001{ }^{* * *} \mathrm{p}<0.0001$.

cancer cells [29,33-40]. Administration of different dosages of melatonin in humans (20-40 mg/day, as single agent or in combination with other drugs) is safe and associates with a significant reduction in risk of death within 1 year for a range of solid cancers [15].

Two major mechanisms have been reported for melatonin's biological activity: G-protein coupled receptor (GPCR) - mediated activity (MT1 and MT2 receptors) and non-receptor-mediated antioxidant activity, because melatonin is highly liposoluble $[41,42]$. MT1 engagement inhibits the activity of adenyl cyclase, decreasing the production of adenosine 3',5'-cyclic monophosphate (cAMP). This in turns modulates the activity of selected protein kinases (PKC, PKA, MAPK), and downstream expression of genes involved in proliferation, angiogenesis, cell differentiation and migration [43]. Both MDA-MB-231 (triple negative subtype) and MCF-7 (estrogen receptor/ER-positive subtype) breast cancer cell lines express MT1 receptor, although lower MT1 expression was reported for triple negative as compared to ER-positive breast cancers $[43,44]$. In addition, pharmacologic concentrations of melatonin may activate other non-receptor mediated pathways [45], which could explain the observed significant inhibition caused by melatonin in the viability of MDA-MB-231 cells.

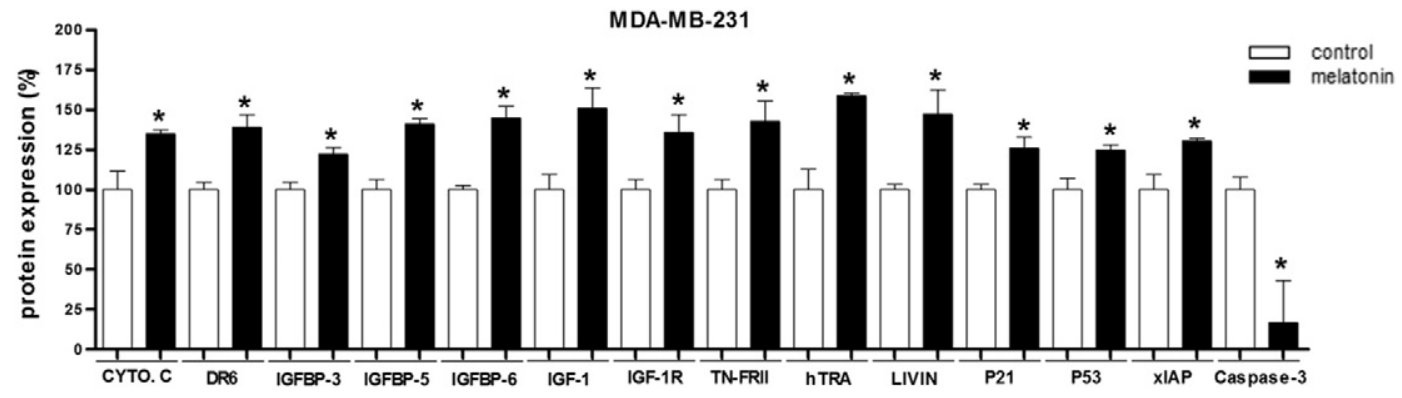

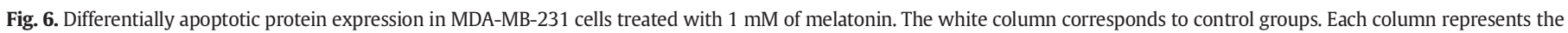
mean \pm standard error of duplicate experiments. ( $\mathrm{p} \leq 0.05$ ). Significance was determined by Student's $t$-test. 


\section{MDA-MB-231}
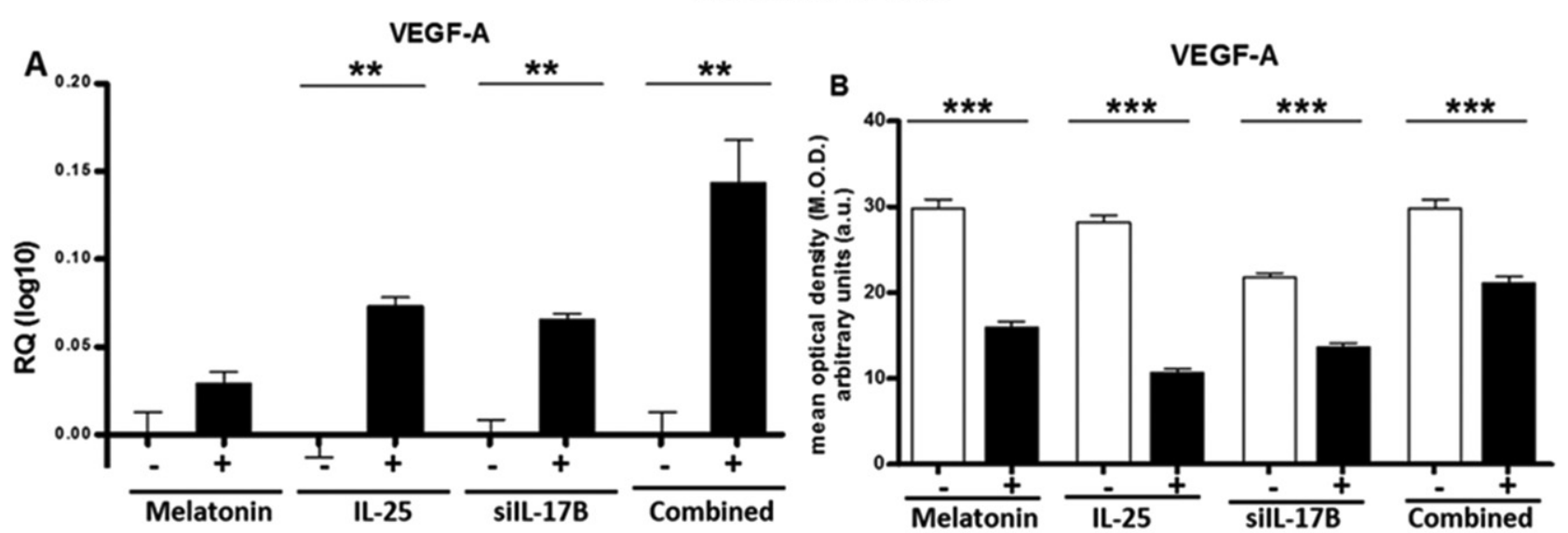

C
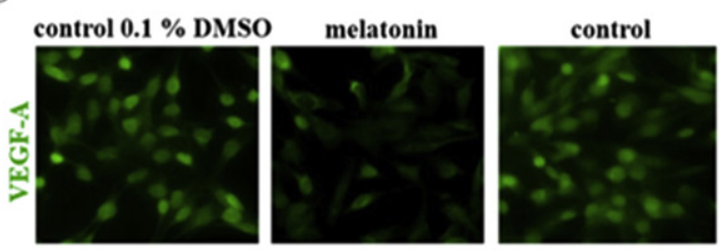

interleukin-25
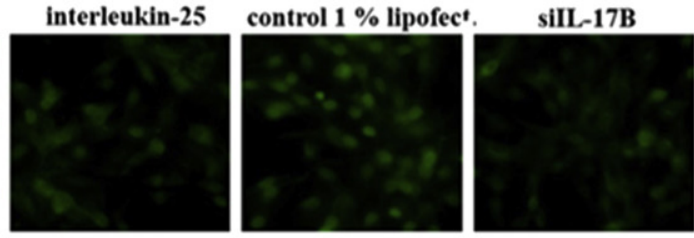

combined
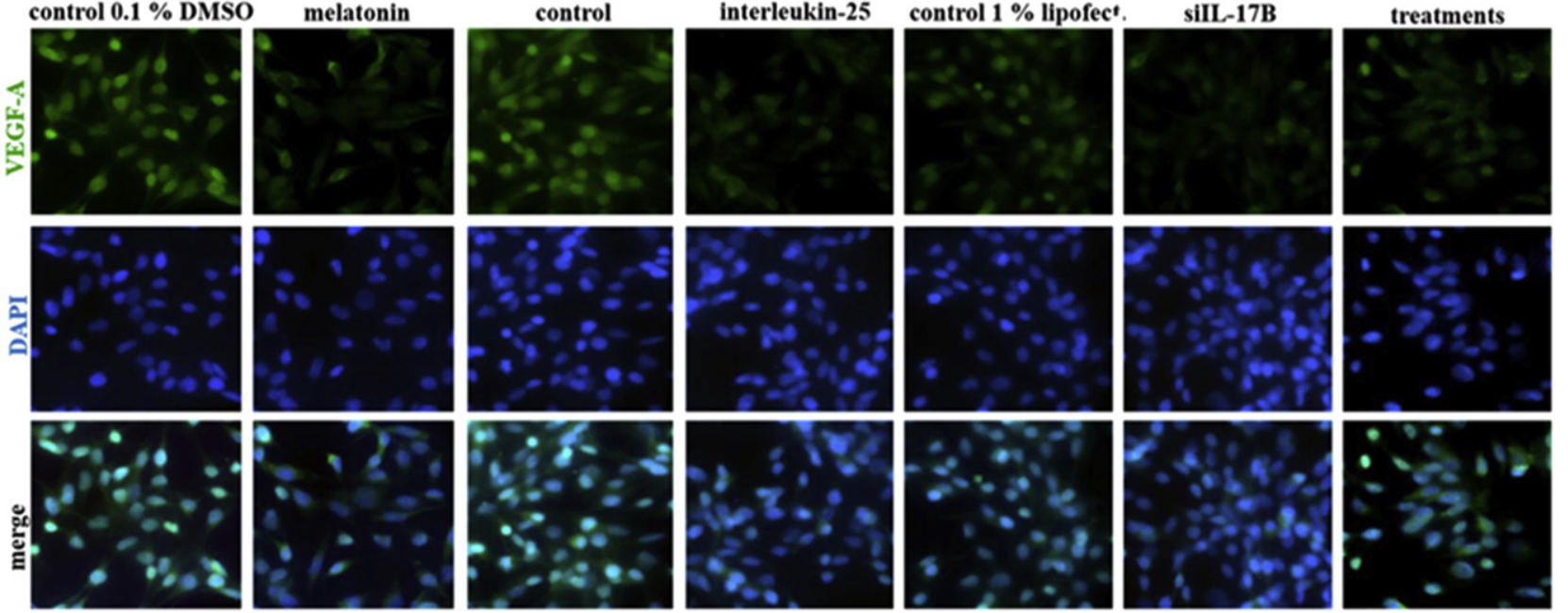

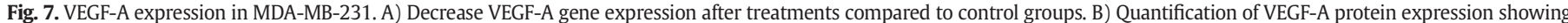

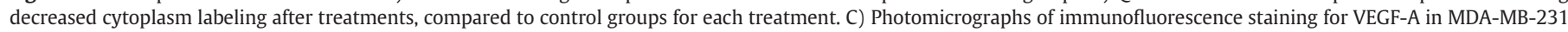

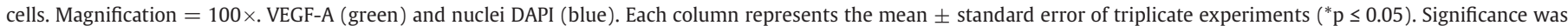
determined by Student's $t$-test. ${ }^{*} \mathrm{p}<0.01{ }^{* *} \mathrm{p}<0.001{ }^{* * *} \mathrm{p}<0.0001$.

We also found that $1 \mathrm{ng} / \mathrm{mL}$ of IL-25 reduced the viability of both MDA-MB-231 and MCF-7 tumor cells. The dose-dependent reduction in cell viability of MDA-MB-231 by IL-25 treatment has not been reported until now; although Furuta et al. [26] showed that MDA-MB-468, a highly metastatic and ER-negative cell line, and MCF-7 cells, are responsive to treatment with $10 \mathrm{ng} / \mathrm{mL}$ of IL-25, a 10-fold higher concentration than the one we used. In addition, IL-25 and a stroma IL-25 inducing agent were shown to significantly hamper breast cancer progression in vivo [46].

On the other hand, we found the absence of an effect of both melatonin and IL-25 on MCF-10A viability; suggesting no cytotoxic potential for these agents in normal luminal breast cells. The results with IL-25 are in agreement with those of Furuta et al. [26], which showed virtually absent expression of IL-25R and resistance to IL-25 treatment in MCF-10A cells. Whether or not the same is true for other normal epithelial cells in the body (thus indicating a reduced probability of side effects) remains to be determined. In this regard, studies with eosinophils indicate that these cells do have receptors for IL-25, and this cytokine enhance their viability and survival $[47,24]$.

Demonstrating the effect of the proposed treatments on apoptosis, we observed enhanced cleaved caspase- 3 protein after each treatment alone and the three combined, in both MDA-MB-231 and MCF-7 monolayer and 3D cultures. Melatonin was previously shown to reduce viability of cancer cells by different mechanisms, including cellular differentiation and apoptotic cell death [39,48-51]. In agreement with our results, di Bella et al. [11] and Sanchez-Hidalgo et al. [52] showed that the direct anti-tumor effect of melatonin occurs via caspase activation, and Rodriguez et al. [53] observed that both the intrinsic and extrinsic apoptosis pathways can be activated by melatonin in cancer cells, but not in normal cells. Induction of apoptosis by IL-25 and/or siL-17B in MCF-7 and MDA-MB-231 cells, as observed here, was also previously reported $[26,27,46,54]$.

In agreement with the observed pro-apoptotic activity of melatonin in metastatic MDA-MB-231 cells, our pilot assessment of the effect of melatonin on apoptosis mediators showed an increase of proteins involved in the extrinsic apoptosis pathway, e.g. TNF-RII and DR6, and in the intrinsic apoptosis pathway, such as CYTO-C. The latter has a crucial role in apoptosis, as upon release into the cytosol it binds apoptotic protease activating factor-1 (APAF-1) and pro-caspase-9, to promote apoptosome formation [55,56]. Wang et al. [57] demonstrated that melatonin induces the expression of APAF- 1 and stimulates the release of CYTO-C, causing the activation of caspases and inducing apoptosis in MDA-MB-361 breast cancer cells.

Growth factors such as IGF-1, IGF-1R and IGFBP-3, -5 and -6 also showed increases after melatonin treatment, in agreement with our previous results [29]. Butt et al. [58] showed that high IGFBP-5 levels correlate with enhanced transcription of pro-apoptotic BAX and a decrease in anti-apoptotic BCL-2, resulting in MDA-MB-231 apoptosis. Interestingly, 
MCF-7
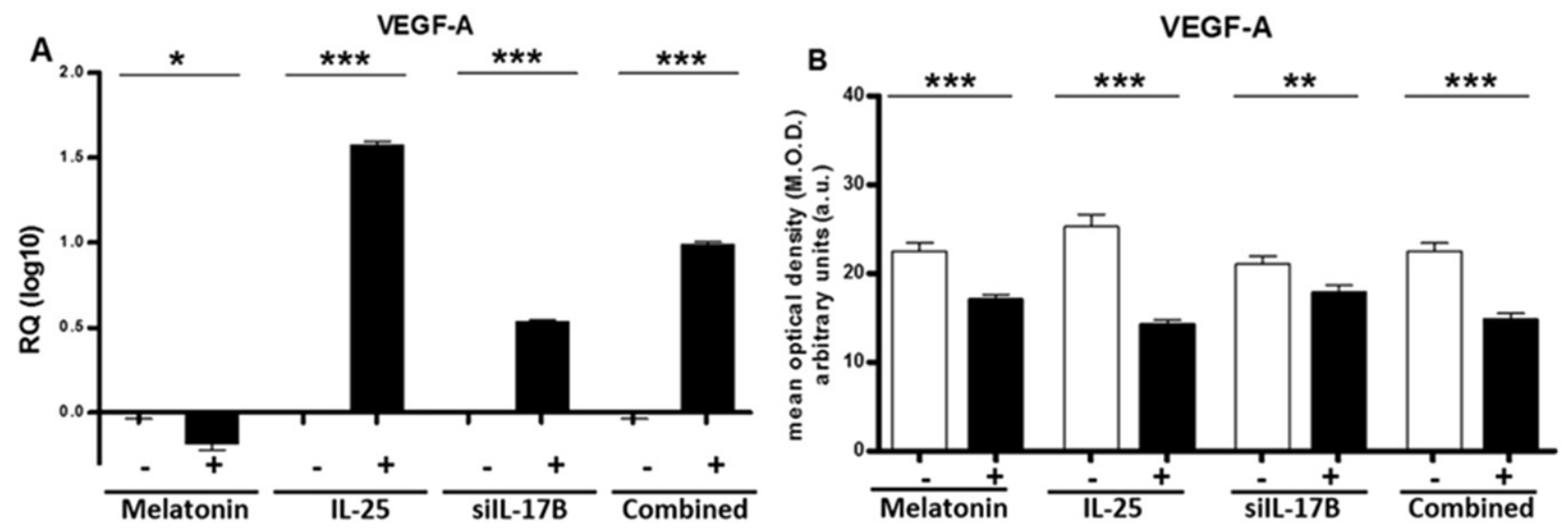

C
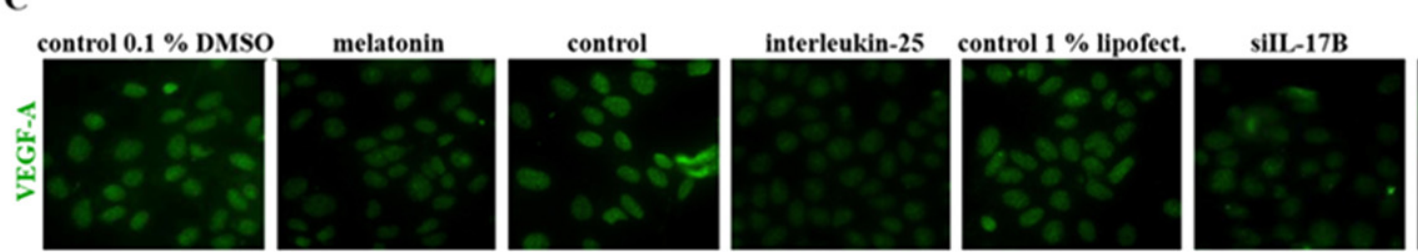

combined
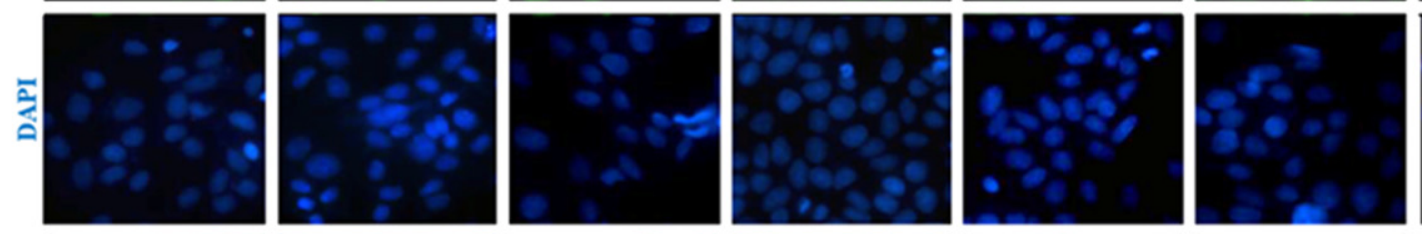

treatments
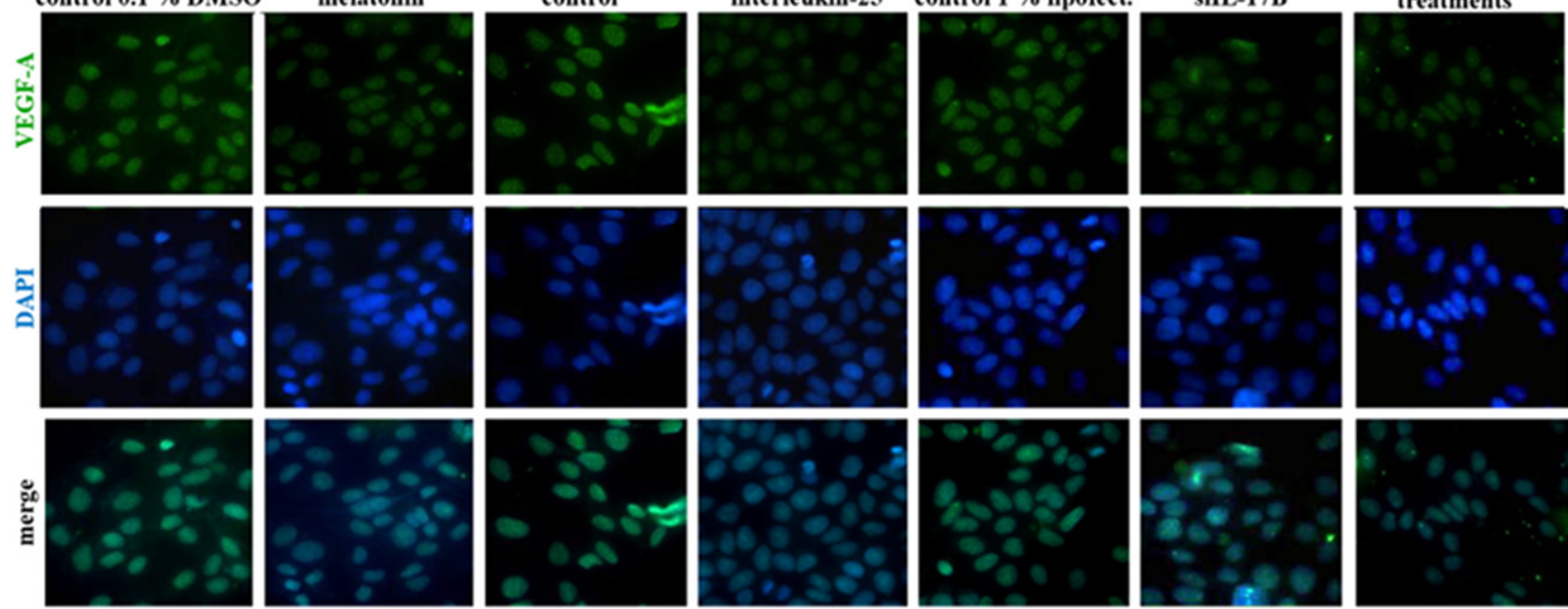

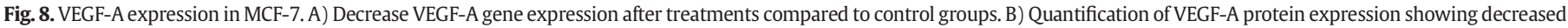

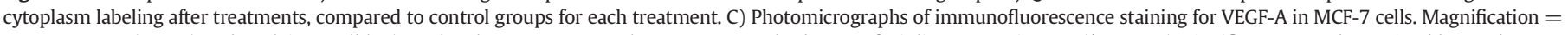

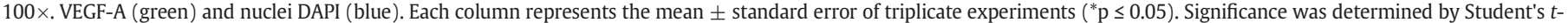
test. ${ }^{*} \mathrm{p}<0.01{ }^{* *} \mathrm{p}<0.001{ }^{* * *} \mathrm{p}<0.0001$.

the anti-apoptotic proteins Livin, XIAP and hTRA were enhanced by melatonin treatment. One possibility is that an increase in survival-promoting molecules occurs as a compensatory mechanism to the major apoptotic stimuli of melatonin. Further studies are necessary to address these possibilities as well as to verify, via Western blotting, the changes in apoptosis mediators observed in this study. The membrane array employed here was meant as a pilot screen to provide a general idea of the apoptosis mediators potentially responsible for melatonin-induced apoptosis, and thus lays the foundation for future mechanistic studies.

Another interesting finding was the observed increase in caspase-3 (CASP3) mRNA in response to all treatments in both MCF7 and MDAMB-231 cells. Modulation of caspase-3 mRNA was previously reported in normal hippocampal neurons of rats treated with melatonin prior to irradiation, where the neuroprotective effect of melatonin associated with a reduction in both caspase- 3 mRNA and caspase- 3 protein cleavage [59]. To the best of our knowledge, ours is the first study to assess the effect of melatonin on caspase-3 mRNA in cancer cells, as most studies examined levels of cleaved caspase- 3 protein. The increase in caspase-3 mRNA could potentially be a compensatory response to caspase- 3 cleavage induced by diverse pro-apoptotic stimuli, and will be important to address in future studies. Similar discrepancies were found for caspase3 protein expression, where melatonin treatment resulted in reduced expression in the membrane array, while it enhanced the expression of its cleaved form (active), as shown by immunofluorescence. A logic explanation for this is the post-translational regulation of the caspase pathway, wherein caspase- 3 is converted into its cleaved form by melatonin treatment, resulting in an increase of the cleaved form at the expense of a reduction of its inactive, full-length form.

Given that melatonin can suppress angiogenesis directly or indirectly [60-62], in both in in vivo and in vitro models [63,64], we also looked at the effect of treatment on VEGF-A expression. VEGF-A is the most active endogenous pro-angiogenic factor, and it is a specific endothelial cell mitogen, also promoting microvascular permeability [65]. In agreement with a study by Dai et al. using MCF-7 cells [61], we observed VEGF-A protein reduction after melatonin treatment in both MCF-7 and MDAMB-231 cells. Carbajo-Pescador et al. [60] proposed that melatonin effects on VEGF expression occur at a post-transcriptional level, which could explain the high, possibly compensatory, VEGF-A mRNA expression after melatonin treatment in MDA-MB-231 cells, as opposed to the reduced VEGF-A protein expression caused by the same treatment in our study. In addition to reduced VEGF protein expression, we previously found [29] lower expression of VEGFR2 and VEGFR3 in melatonin-treated compared to vehicle-treated breast cancer xenografts, which associated with significantly reduced microvascular density. Another study [66] 
showed a decrease in a number of pro-angiogenic proteins, including EGF, ENA-78, bFGF, IL-8, Leptin, MCP-1 and PDGF-BB, in MDA-MB-231 cells treated with melatonin.

Complementary to the aforementioned findings, melatonin was also found to suppress HIF- $1 \alpha$ transcriptional activity during hypoxia [67]. In this regard, it will be interesting to address whether the G13D K-ras mutation that exists in MDA-MB-231 cells [68] could be responsible for the different effect of melatonin of VEGF mRNA expression in MCF-7 versus MDA-MB-231 cells, as mutant over-active RAS is a potent inducer on VEGF-A transcription in epithelial cells, in part by inducing HIF- $1 \alpha$ protein expression [69]. In our study, IL-25 and silL-17B treatments also reduced VEGF-A protein expression in breast cancer cells, although addition of these treatments to melatonin did not significantly enhance the effect of the latter. Studies looking specifically at IL-25 effect on angiogenesis mediators in cancer cells are scarce. Several studies reported correlations between IL-17 family expression and microvessel density in human ovarian cancer [70], hepatocellular carcinoma [71], and nonsmall-cell lung carcinoma [72]. According to Liu et al. [73] and Maniati and Hagemann [74], IL-17 (a.k.a. IL-17A) can modulate angiogenesis directly (through IL-17R binding on endothelial cells), or indirectly, by stimulating cancer cells to produce angiogenic factors, including VEGF.

Finally, it is noteworthy that we did not observe a significant enhancement of pro-apoptotic or VEGF-reducing effects by combined engagement of IL-25/IL-17RB signaling with melatonin. Possible explanations for this could be an overlapping mechanism of action of the two approaches, or inadequate timing of combination of the different targeting modalities. A better understanding of the mechanism of action of IL-25 will facilitate the design of single or combined agent strategies for effective tumor targeting in the future.

\section{Conclusions}

Our study demonstrated the independent efficacy of melatonin and IL-25 in reducing cell viability of ER-positive and triple negative breast cancer cell lines with minimal effect on non-tumorigenic cells. In addition, melatonin treatment or the modulation of interleukins 25/17E and 17B promoted apoptosis in both monolayer and three-dimensional cultures, and reduced VEGF-A protein expression. Although the combined treatments did not significantly enhance the individual effects of the tested approaches, our results independently confirm the effectiveness of melatonin and IL-25/silL-17B as individual agents with a dual capacity to enhance apoptosis and potentially inhibit angiogenesis. Future combination approaches should aim at enhancing these capacities by targeting possible compensatory pathways.

\section{Conflict of interest statement}

The authors declare that they have no competing interests.

\section{Funding}

This research was funded by the Fundacao de Amparo a Pesquisa do Estado de Sao Paulo - FAPESP (grants \# 2012/06098-0 and 2012/021281) and Fundacao de Apoio a Pesquisa e Extensao de Sao Jose do Rio Preto - FAPERP (grant \# 175/2014). The Laboratory of Molecular Research in Cancer (LIMC, FAMERP, Brazil) and the Laboratory for Integrated Study of the Mechanisms of Breast Cancer Invasion and Metastasis (University of Guelph, Canada) provided the infrastructure to carry out this project. The latter was funded by a Canadian Foundation for Innovation (CFI; project \# 26742) and Ministry of Research Infrastructure (MRI, Ontario; grant \# 460342) grant to A.V.P.

\section{Authors' contributions}

GBG designed the study, carried out all experiments assessing cell response to treatments, including qRT-PCR, immunofluorescence staining, and statistical analysis, and drafted the manuscript. TFB participated in experimental design, gene silencing and qRT-PCR experiments, and revised the manuscript. LBM carried out the membrane array assay and analyzed the results. MGM and BVJ carried out the cell viability assay, contributed to the interpretation of results and revised the manuscript. GBC and MCF helped with monolayer and tridimensional cell cultures and with the interpretation of results. AMVP supervised the research, helped with the immunofluorescence staining, analysis and interpretation of results, and drafted the manuscript. DAPCZ conceived and designed the study, coordinated the research, helped with result interpretation and drafted the manuscript. All authors read and approved all aspects of the final manuscript.

\section{Acknowledgements}

We thank Lívia Carvalho Ferreira, Camila Leonel and Gustavo Rodrigues Martins for their help with manuscript writing and editing, and Dr. Patricia Simone Leite Vilamaior for helping in capture and processing of confocal 3D images (ZEISS, model LSM 710, software ZEN 2010, Thornwood, NY, USA).

\section{References}

[1] O.E. Franco, A.K. Shaw, D.W. Strand, et al., Cancer associated fibroblasts in cancer pathogenesis, Semin. Cell Dev. Biol. 21 (2010) 33-39.

[2] I. Lühr, A. Friedl, T. Overath, et al., Mammary fibroblasts regulate morphogenesis of normal and tumorigenic breast epithelial cells by mechanical and paracrine signals, Cancer Lett. 325 (2012) 175-188.

[3] M. Król, K.M. Pawłowski, K. Szyszko, et al., The gene expression profiles of canine mammary cancer cells grown with carcinoma-associated fibroblasts (CAFs) as a co-culture in vitro, BMC Vet. Res. 8 (2012) 8-35.

[4] L.M. Coussens, Werb Z inflammation and cancer, Nature 420 (2002) 860-867.

[5] M.A. Folgueira, S. Maistro, M.L. Katayama, et al., Markers of breast cancer stromal fibroblasts in the primary tumour site associated with lymph node metastasis: a systematic review including our case series, Biosci. Rep. 33 (2013).

[6] J.C. Porretti, N.A. Mohamad, G.A. Martín, et al., Fibroblasts induce epithelial to mesenchymal transition in breast tumor cells which is prevented by fibroblasts treatment with histamine in high concentration, Int. J. Biochem. Cell Biol. 51 (2014) 29-38.

[7] K. Haim, P. Weitzenfeld, T. Meshel, et al., Epidermal growth factor and estrogen act by independent pathways to additively promote the release of the angiogenic chemokine CXCL8 by breast tumor cells, Neoplasia 13 (2011) 230-243.

[8] R. Ordoñez, S. Carbajo-Pescador, N. Prieto-Dominguez, et al., Inhibition of matrix metalloproteinase-9 and nuclear factor kappa B contribute to melatonin prevention of motility and invasiveness in HepG2 liver cancer cells, J. Pineal Res. 56 (2014) 20-30.

[9] F. Luchetti, B. Canonico, M. Betti, et al., Melatonin signaling and cell protection function, FASEB J. 24 (2010) 3603-3624.

[10] V. Alvarez-García, A. González, C. Alonso-González, et al., Melatonin interferes in the desmoplastic reaction in breast cancer by regulating cytokine production, J. Pineal Res. 52 (2012) 282-290.

[11] G. di Bella, F. Mascia, L. Gualano, et al., Melatonin anticancer effects: review, Int. J. Mol. Sci. 14 (2013) 2410-2430.

[12] M. Fic, M. Podhorska-Okolow, P. Dziegiel, et al., Effect of melatonin on cytotoxicity of doxorubicin toward selected cell lines (human keratinocytes, lung cancer cell line A549, laryngeal cancer cell line Hep-2), In Vivo 21 (2007) 513-518.

[13] S. Mirunalini, G. Dhamodharan, Studies on the chemopreventive potential of melatonin on 7,12-dimethylbenz(a)anthracene induced mammary carcinogenesis in rats, J. Appl. Sci. Res. (2010) 245-253.

[14] M.D. Mediavilla, E.J. Sanchez-Barcelo, D.X. Tan, et al., Basic mechanisms involved in the anti-cancer effects of melatonin, Curr. Med. Chem. 17 (2010) 4462-4481.

[15] P. Lissoni, S. Barni, M. Mandalà, et al., Decreased toxicity and increased efficacy of cancer chemotherapy using the pineal hormone melatonin in metastatic solid tumour patients with poor clinical status, Eur. J. Cancer 35 (1999) 1688-1692.

[16] E.J. Sánchez-Barceló, S. Cos, D. Mediavilla, et al., Melatonin-estrogen interactions in breast cancer, J. Pineal Res. 38 (2005) 217-222.

[17] S. Proietti, A. Cucina, R.J. Reiter, et al., Molecular mechanisms of melatonin's inhibitory actions on breast cancers, Cell. Mol. Life Sci. 70 (2013) 2139-2157.

[18] H. Sasaki, S. Fukuda, H. Otani, et al., Hypoxic preconditioning triggers myocardial angiogenesis: a novel approach to enhance contractile functional reserve in rat with myocardial infarction, J. Mol. Cell. Cardiol. 34 (2002) 335-348.

[19] W.D. Li, T.S. Liu, Q.J. Yao, et al., Correlation between the activation of AP-1 signal transduction pathway and metastasis of colorectal carcinoma, Zhonghua Wei Chang Wai Ke Za Zhi 8 (2005) 356-359.

[20] A. Korkmaz, S. Rosales-Corral, Reiter RJ Gene regulation by melatonin linked to epigenetic phenomena, Gene 503 (2012) 1-11.

[21] S. Aggarwal, A.L. Gurney, IL-17: prototype member of an emerging cytokine family, J. Leukoc. Biol. 71 (2002) 1-8.

[22] Y. Maezawa, H. Nakajima, K. Suzuki, et al., Involvement of TNF receptor-associated factor 6 in IL-25 receptor signaling, J. Immunol. 176 (2006) 1013-1018. 
[23] D.E. Lyon, N.L. McCain, J. Walter, et al., Cytokine comparisons between women with breast cancer and women with a negative breast biopsy, Nurs. Res. 57 (2008) 51-58.

[24] T. Benatar, M.Y. Cao, Y. Lee, et al., IL-17E, a proinflammatory cytokine, has antitumor efficacy against several tumor types in vivo, Cancer Immunol. Immunother. 59 (2010) 805-817.

[25] I. Kryczek, K. Wu, E. Zhao, et al., IL-17 + regulatory T cells in the microenvironments of chronic inflammation and cancer, J. Immunol. 186 (2011) 4388-4395.

[26] S. Furuta, Y.M. Jeng. L. Zhou, et al., IL-25 causes apoptosis of IL-25R-expressing breast cancer cells without toxicity to nonmalignant cells, Sci. Transl. Med. 3 (2011) 7831.

[27] C.K. Huang, C.Y. Yang, Y.M. Jeng, et al., Autocrine/paracrine mechanism of interleukin17B receptor promotes breast tumorigenesis through NF-kB-mediated antiapoptotic pathway, Oncogene 33 (2014) 2968-2977.

[28] T.D. Schmittgen, K.J. Livak, Analyzing real-time PCR data by the comparative C(T) method, Nat. Protoc. 3 (2008) 1101-1108.

[29] B.V. Jardim-Perassi, A.S. Arbab, L.C. Ferreira, et al., Effect of melatonin on tumor growth and angiogenesis in xenograft model of breast cancer, PLoS One 9 (2014) e85311.

[30] B.V. Jardim-Perassi, M.R. Lourenco, G.M. Doho, et al., Melatonin regulates Angiogenic factors under hypoxia in breast cancer cell lines, Anti Cancer Agents Med. Chem. 16 (3) (2016) 347-358.

[31] T.F. Borin, A.S. Arbab, G.B. Gelaleti, et al., Melatonin decreases breast cancer metastasis by modulating Rho-associated kinase protein-1 expression, J. Pineal Res. 60 (2016) 3-15.

[32] Amaral JBd, Células MCF-7 como modelo 3D no estudo do câncer de mama humano, Biologia celular e teciadual, Sao Paulo University, Biomedical Sciences Institute 2010, p. 43 (Thesis USP).

[33] S.M. Hill, D.E. Blask, Effects of the pineal hormone melatonin on the proliferation and morphological characteristics of human breast cancer cells (MCF-7) in culture, Cancer Res. 48 (1988) 6121-6126.

[34] D.E. Blask, S.M. Hill, Effects of melatonin on cancer: studies on MCF-7 human breast cancer cells in culture, J. Neural Transm. Suppl. 21 (1986) 433-449.

[35] S. Cos, R. Fernández, A. Güézmes, et al., Influence of melatonin on invasive and metastatic properties of MCF-7 human breast cancer cells, Cancer Res. 58 (1998) 4383-4390.

[36] K.M. Eck, L. Yuan, L. Duffy, et al., A sequential treatment regimen with melatonin and all-trans retinoic acid induces apoptosis in MCF-7 tumour cells, Br. J. Cancer 77 (1998) 2129-2137.

[37] L. Yuan, A.R. Collins, J. Dai, et al., MT(1) melatonin receptor overexpression enhances the growth suppressive effect of melatonin in human breast cancer cells, Mol. Cell. Endocrinol. 192 (2002) 147-156.

[38] L. Mao, Q. Cheng, B. Guardiola-Lemaître, et al., In vitro and in vivo antitumor activity of melatonin receptor agonists, J. Pineal Res. 49 (2010) 210-221.

[39] A. Cucina, S. Proietti, F. D'Anselmi, et al., Evidence for a biphasic apoptotic pathway induced by melatonin in MCF-7 breast cancer cells, J. Pineal Res. 46 (2009) 172-180.

[40] E.S. Leman, B.F. Sisken, S. Zimmer, et al., Studies of the interactions between melatonin and $2 \mathrm{~Hz}, 0.3 \mathrm{mT}$ PEMF on the proliferation and invasion of human breast cancer cells, Bioelectromagnetics 22 (2001) 178-184.

[41] M.L. Dubocovich, Melatonin receptors: role on sleep and circadian rhythm regulation, Sleep Med. 8 (Suppl. 3) (2007) 34-42.

[42] S.M. Hill, V.P. Belancio, R.T. Dauchy, et al., Melatonin: an inhibitor of breast cancer, Endocr. Relat. Cancer 22 (2015) R183-R204.

[43] K. Jablonska, B. Pula, A. Zemla, et al., Expression of melatonin receptor MT1 in cells of human invasive ductal breast carcinoma, J. Pineal Res. 54 (2013) 334-345.

[44] G. Oprea-Ilies, E. Haus, L. Sackett-Lundeen, et al., Expression of melatonin receptors in triple negative breast cancer (TNBC) in African American and Caucasian women: relation to survival, Breast Cancer Res. Treat. 137 (2013) 677-687.

[45] P.T. Ram, T. Kiefer, M. Silverman, et al., Estrogen receptor transactivation in MCF-7 breast cancer cells by melatonin and growth factors, Mol. Cell. Endocrinol. 141 (1998) 53-64.

[46] Y. Shu-Yi, J. Feng-Yin, C. Yung-Hsiang, et al., Induction of IL-25 secretion from tumour associated fibroblasts suppresses mammary tumour metastasis, Nat. Commun. 7 (2016) 11311

[47] C.K. Wong, P.F. Cheung, W.K. Ip, et al., Interleukin-25-induced chemokines and interleukin- 6 release from eosinophils is mediated by p38 mitogen-activated protein kinase, c-Jun N-terminal kinase, and nuclear factor-kappaB, Am. J. Respir. Cell Mol. Biol. 33 (2005) 186-194.

[48] J. Perdomo, J. Cabrera, F. Estévez, et al., Melatonin induces apoptosis through a caspase-dependent but reactive oxygen species-independent mechanism in human leukemia molt-3 cells, J. Pineal Res. 55 (2013) 195-206.

[49] P. Plaimee, N. Weerapreeyakul, S. Barusrux, et al., Melatonin potentiates cisplatininduced apoptosis and cell cycle arrest in human lung adenocarcinoma cells, Cel Prolif. 48 (2015) 67-77.
[50] S. Proietti, A. Cucina, G. Dobrowolny, et al., Melatonin down-regulates MDM2 gene expression and enhances p53 acetylation in MCF-7 cells, J. Pineal Res. 57 (2014) $120-129$.

[51] A. Korkmaz, H. Tamura, L.C. Manchester, et al., Combination of melatonin and a peroxisome proliferator-activated receptor-gamma agonist induces apoptosis in a breast cancer cell line, J. Pineal Res. 46 (2009) 115-116.

[52] M. Sánchez-Hidalgo, M. Lee, C.A. de la Lastra, et al., Melatonin inhibits cell proliferation and induces caspase activation and apoptosis in human malignant lymphoid cell lines, J. Pineal Res. 53 (2012) 366-373.

[53] C. Rodriguez, V. Martín, F. Herrera, et al., Mechanisms involved in the pro-apoptotic effect of melatonin in cancer cells, Int. J. Mol. Sci. 14 (2013) 6597-6613.

[54] V. Younesi, F. Netajollahi, Induction of anti-proliferative and apoptotic effects by antiIL-25 receptor single chain antibodies in breast cancer cells, Int. Immunopharmacol. 23 (2014) 624-632.

[55] M. Hüttemann, P. Pecina, M. Rainbolt, et al, The multiple functions of cytochrome c and their regulation in life and death decisions of the mammalian cell: from respiration to apoptosis, Mitochondrion 11 (2011) 369-381.

[56] J. Chen, W. Wang, H. Wang, et al., Combination treatment of ligustrazine piperazine derivate DLJ14 and adriamycin inhibits progression of resistant breast cancer through inhibition of the EGFR/PI3K/Akt survival pathway and induction of apoptosis, Drug Discov Ther. 8 (2014) 33-41.

[57] J. Wang, X. Xiao, Y. Zhang, et al., Simultaneous modulation of COX-2, p300, Akt, and Apaf-1 signaling by melatonin to inhibit proliferation and induce apoptosis in breast cancer cells, J. Pineal Res. 53 (2012) 77-90.

[58] A.J. Butt, K.A. Dickson, F. McDougall, et al., Insulin-like growth factor-binding protein5 inhibits the growth of human breast cancer cells in vitro and in vivo, J. Biol. Chem. 278 (2003) 29676-29685.

[59] J. Li, G. Zhang, A. Meng, et al., Neuroprotective effect of acute melatonin treatment on hippocampal neurons against irradiation by inhibition of caspase-3, Exp Ther. Med. 11 (6) (2016) 2385-2390.

[60] S. Carbajo-Pescador, A. García-Palomo, J. Martín-Renedo, et al., Melatonin modulation of intracellular signaling pathways in hepatocarcinoma HepG2 cell line: role of the MT1 receptor, J. Pineal Res. 51 (2011) 463-471.

[61] M. Dai, P. Cui, M. Yu, et al., Melatonin modulates the expression of VEGF and HIF-1 alpha induced by CoCl2 in cultured cancer cells, J. Pineal Res. 44 (2008) 121-126.

[62] V. Alvarez-García, A. González, C. Alonso-González, et al., Antiangiogenic effects of melatonin in endothelial cell cultures, Microvasc. Res. 87 (2013) 25-33.

[63] S.Y. Cho, H.J. Lee, S.J. Jeong, et al., Sphingosine kinase 1 pathway is involved in melatonin-induced HIF- $1 \alpha$ inactivation in hypoxic PC-3 prostate cancer cells, J. Pineal Res. 51 (2011) 87-93.

[64] P. Cui, M. Yu, X. Peng, et al., Melatonin prevents human pancreatic carcinoma cell PANC-1-induced human umbilical vein endothelial cell proliferation and migration by inhibiting vascular endothelial growth factor expression, J. Pineal Res. 52 (2012) 236-243.

[65] H. Xin, C. Zhong, E. Nudleman, et al., Evidence for pro-angiogenic functions of VEGFax, Cell 167 (1) (2016) 275-284.

[66] L.B. Maschio-Signorini, G.B. Gelaleti, M.G. Moschetta, et al., Melatonin regulates angiogenic and inflammatory proteins in MDA-MB-231 cell line and in co-culture with cancer-associated fibroblasts, Anti Cancer Agents Med. Chem. 16 (11) (2016) 1474-1484.

[67] S.Y. Park, W.J. Jang, E.Y. Yi, et al., Melatonin suppresses tumor angiogenesis by inhibiting HIF-1alpha stabilization under hypoxia, J. Pineal Res. 48 (2010) 178-184.

[68] S.C. Kozma, M.E. Bogaard, K. Buser, et al., The human c-Kirsten ras gene is activated by a novel mutation in codon 13 in the breast carcinoma cell line MDA-MB231, Nucleic Acids Res. 15 (1987) 1-5971.

[69] C. Blancher, J.W. Moore, N. Robertson, et al., Effects of ras and von Hipperl-Lindau (VHL) gene mutations on hypoxia-inducible factor (HIF)-1 alpha, HIF-2alpha, and vascular endothelial growth factor expression and their regulation by phosphatidylinositol 3'-kinase/Akt signaling pathway, Cancer Res. 61 (2001) 7349-7355.

[70] T. Kato, H. Furumoto, T. Ogura, et al., Expression of IL-17 mRNA in ovarian cancer, Biochem. Biophys. Res. Commun. 282 (2001) 735-738.

[71] J.P. Zhang, J. Yan, J. Xu, et al., Increased intratumoral IL-17-producing cells correlate with poor survival in hepatocellular carcinoma patients, J. Hepatol. 50 (2009) 980-989.

[72] M. Numasaki, M. Watanabe, T. Suzuki, et al., IL-17 enhances the net angiogenic activity and in vivo growth of human non-small cell lung cancer in SCID mice through promoting CXCR-2-dependent angiogenesis, J. Immunol. 175 (2005) 6177-6189.

[73] J. Liu, Y. Duan, X. Cheng, et al., IL-17 is associated with poor prognosis and promotes angiogenesis via stimulating VEGF production of cancer cells in colorectal carcinoma, Biochem. Biophys. Res. Commun. 407 (2011) 348-354.

[74] E. Maniati, Hagemann T IL-17 mediates resistance to anti-VEGF therapy, Nat. Med. 19 (2013) 1092-1094. 